\title{
Faculty Perceptions of Readiness to Implement Interprofessional Education in Athletic Training
}

\author{
Meredith M. Parry \\ University of St. Augustine for Health Sciences \\ DOI: https://doi.org/10.46409/sr.PIOB4957
}

Follow this and additional works at: https://soar.usa.edu/dissertations

Part of the Interprofessional Education Commons, and the Sports Medicine Commons

\section{Recommended Citation}

Parry, M. M. (2017). Faculty Perceptions of Readiness to Implement Interprofessional Education in Athletic Training. [Doctoral project, University of St Augustine for Health Sciences]. SOAR @ USA: Student Dissertations Collection. https://doi.org/10.46409/sr.PIOB4957 
Faculty Perceptions of Readiness to Implement Interprofessional Education in Athletic Training

A dissertation submitted in partial fulfillment of the requirements for the degree of Doctor of Education at the University of St. Augustine for Health Sciences

Meredith M. Parry, MS, ATC 


\begin{abstract}
As the athletic training profession takes steps towards the next level as an allied health care profession, advocates for the profession are positioning athletic trainers as key players in the interprofessional health care team. Recently, the CAATE has pronounced a move for athletic training education to transition all entry-level education to professional master's degree programs. CAATE is also requesting that athletic training education programs find means to align with other healthcare profession education programs within their institution and actively engage in planned and continuous interprofessional learning activities. This study explored the gap in knowledge regarding athletic training faculty perceptions on their readiness to implement IPE. Data was collected using an electronic survey administered to athletic training program faculty. The objectives of the study were to explore athletic training educators' perceptions of knowledge, beliefs, and barriers related to IPE. The results of this study identified that differences exist in faculty perceptions of IPE based on faculty rank or role, years of teaching experience, skill level using IPE, previous experience with using IPE, and geographical location of ATEPs within the institution. Together, the findings suggest that IPE integration should include initiatives that provide administrative support, delineated leadership roles and efforts for bringing allied health disciplines in closer physical proximity on their campuses.

Keywords: IPE, athletic training, faculty, barriers
\end{abstract}




\author{
WE, THE UNDERSIGNED MEMBERS OF THE COMMITTEE, HAVE APPROVED \\ THIS DISSERTATION IN PARTIAL FULFILLMENT OF THE REQUIREMENTS \\ FOR THE DEGREE \\ DOCTOR OF EDUCATION
}

\title{
Faculty Perceptions of Readiness to Implement Interprofessional Education in Athletic Training
}

By:

Meredith M. Parry

COMMITTEE MEMBERS

\section{Dr. Jordan Utigitally signed by Dr. Jordan Utley, PhD,

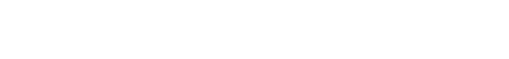 \\ PhD, LAT, ATC

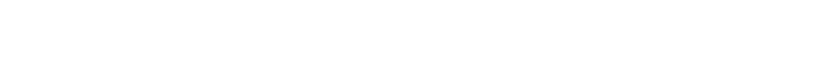

$6 / 15 / 2017$

Jordan Utley, $\mathrm{PhD}$

Date

Program Director, Associate Professor

Master of Health Science

University of St. Augustine

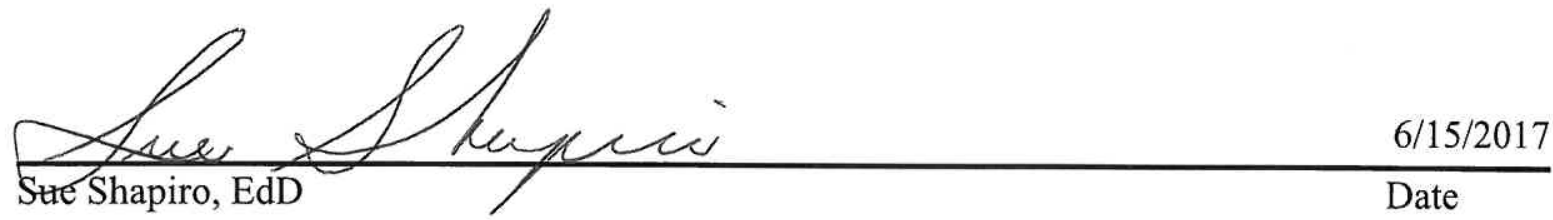

Program Director, Associate Professor

Undergraduate \& Graduate Athletic Training Program

Barry University

ACCEPTED AND APPROVED ON BEHALF OF THE UNIVERSITY

\section{Dr. Cindy Digitally signed by Dr. Cindy Mathena \\ DN: cn=Dr.c Cindy Mathena, o=Univa
of St. Augustine for Health Science, \\ $\begin{array}{ll}\text { Mathena } & \begin{array}{l}\text { ou=Dean of Post Professional Studies, } \\ \text { email=cmathena@usa.ued, } c=U \mathrm{~S} \\ \text { Date: } 2018.02 .0115: 11: 26-05^{\prime} 00^{\prime}\end{array}\end{array}$}

Cindy Mathena, PhD, OTR/L

Dean of Post Professional Studies

University of Saint Augustine for Health Sciences 


\section{$\underline{\text { Acknowledgements }}$}

Even though this paper is a result of my hard work and dedication, it would not have been possible without the guidance and support from the following people:

USA for Health Science Doctoral Program Faculty and Administrators - This program provided me with access to collaborate with a unique and diverse group of educators who had the compassion to cater to my individual educational needs. Without the flexibility and support of this program, my dreams of completing doctorate would not have been possible. THANK YOU!

Dr. Jordan Utley - Through your guidance and support you made this process an illuminating experience of knowledge acquisition and self-discovery. Thank you for keeping up with my tireless determination to press forward at top speed. Without your leadership as Committee Chair, this final product would not be possible. THANK YOU!

Dr. Sue Shapiro -You have been my idol since the first day I stepped onto Barry's campus as an undergraduate athletic training student. From that day forward, I have been fortunate to have been showered with your gift of valued mentorship and now, more importantly, your friendship. I truly owe you all the acknowledgement for the professional woman I am today. THANK YOU for all the tough love.

Dr. Kathy Ludwig - Thank you for catching me when I started to fall. THANK YOU for believing in me and trusting in my abilities to make it this far.

My Dear Friends and Family - Thank you for putting up with my absence over the years. You all have been supportive of my professional goals from the beginning. Thank you for sticking by my side, providing encouragement through the disappointments and, more importantly, being there to celebrate the triumphs. THANK YOU!

Mom - You are the reason I aspired to be the woman I am today. You taught me to be a resilient and independent woman. You have taught me to stay positive, and when all else fails, "Go for a run and say a few prayers." Thank you for putting up with my "Sunday visits" that consisted of me and my computer screen at the kitchen counter, as you gave me support through good food and clean laundry. You are my rock, without you, nothing I have today would be possible. THANK YOU! 
Table of Contents

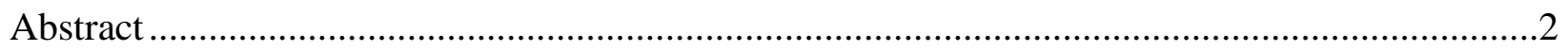

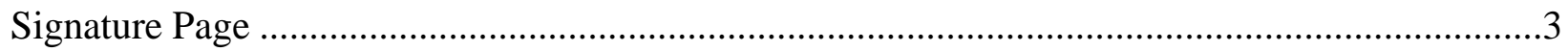

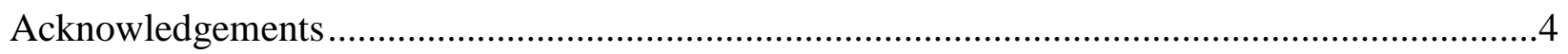

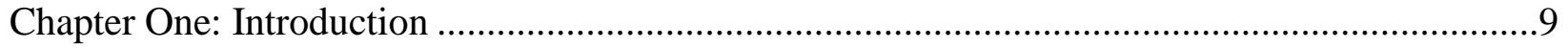

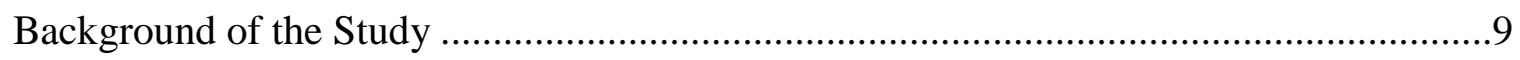

Statement of the Problem..........................................................................................10

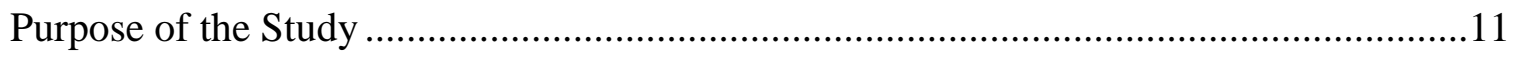

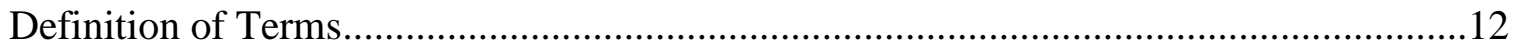

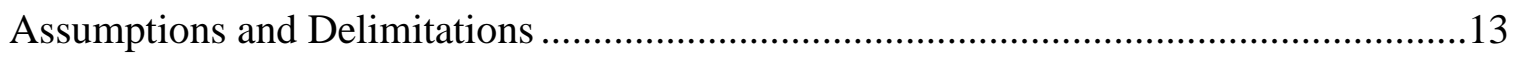

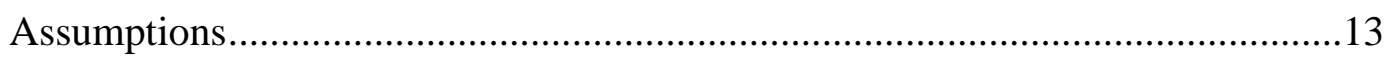

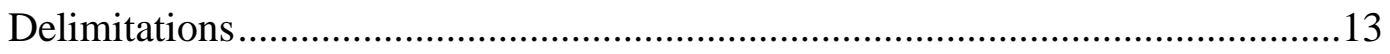

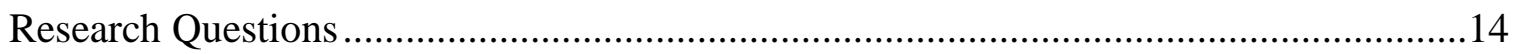

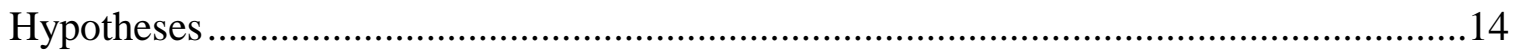

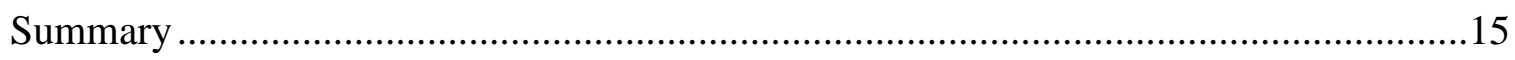

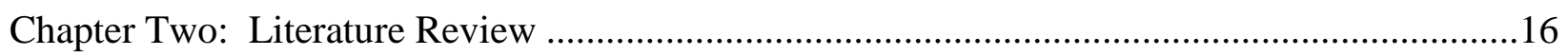

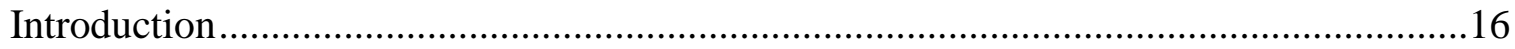

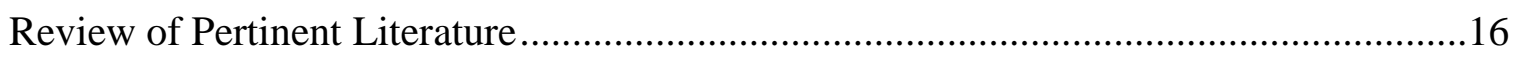

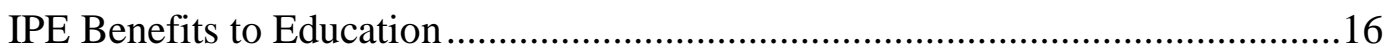

Efforts for Effective Implementation.............................................................18

The Evolution of Athletic Training Education .................................................19

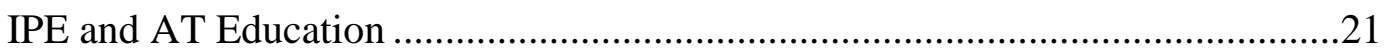

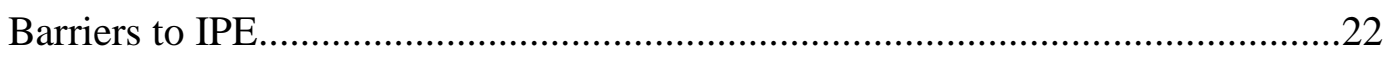

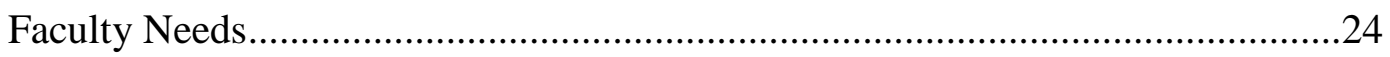

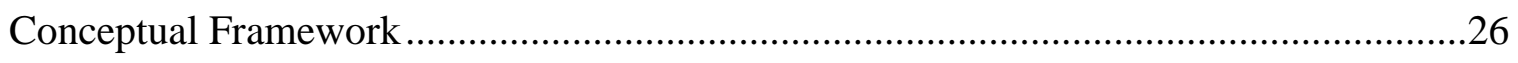

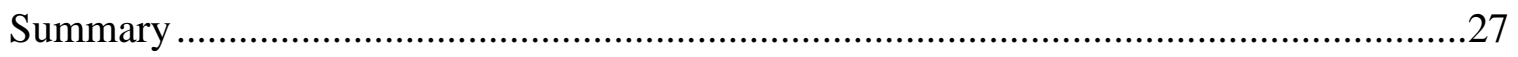

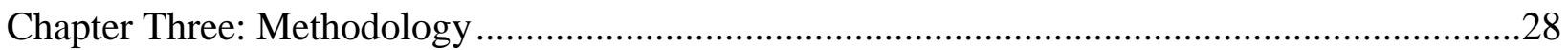

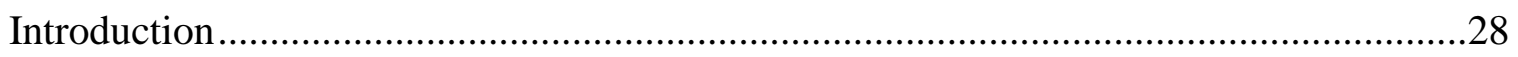

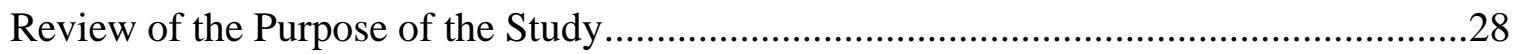

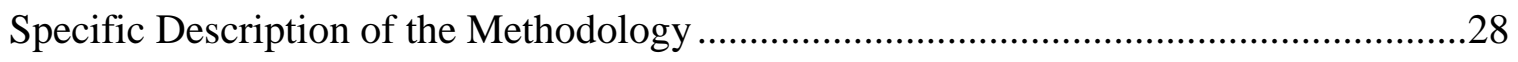

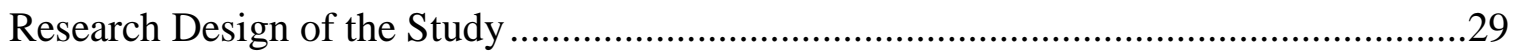

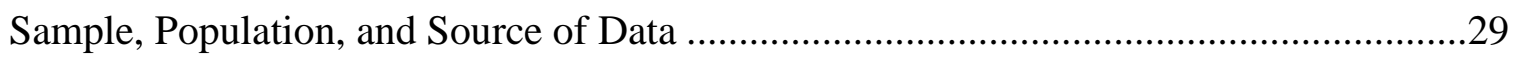

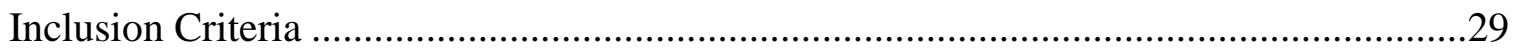

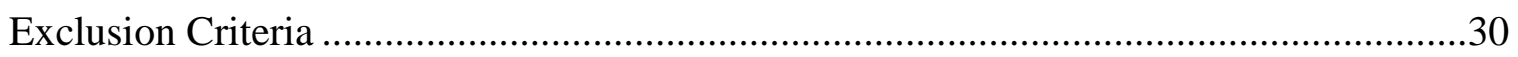

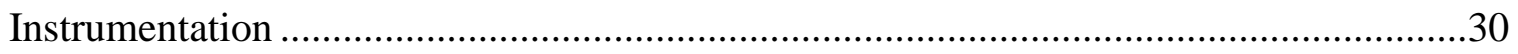

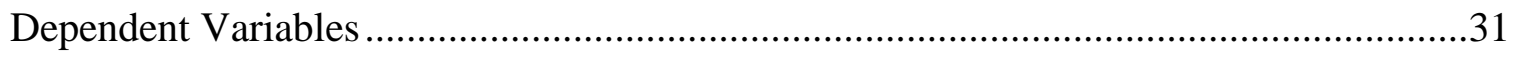

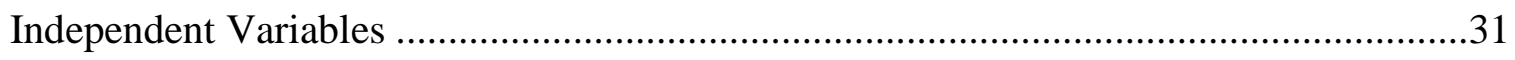

Informed Consent Process ...................................................................................... 


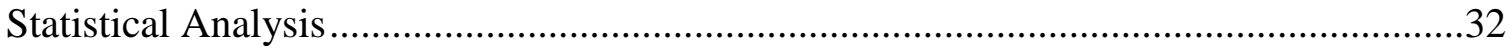

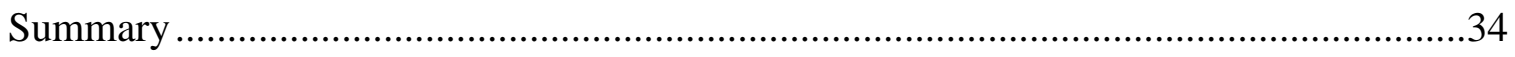

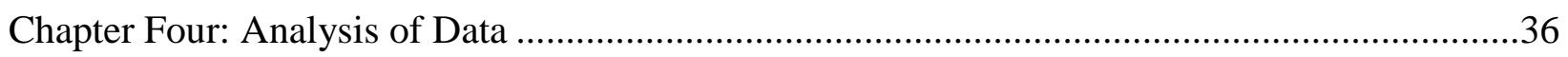

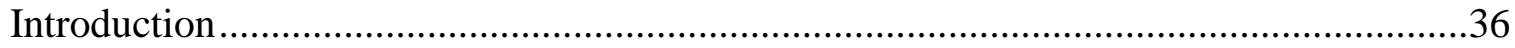

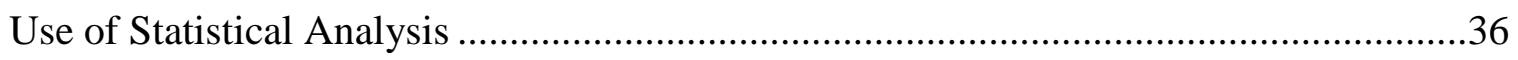

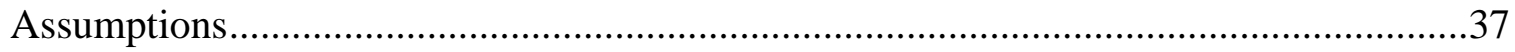

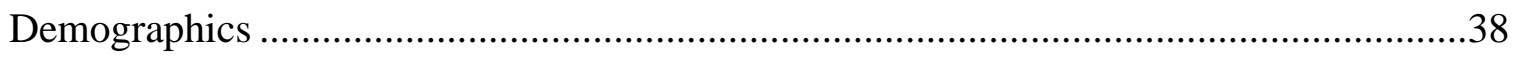

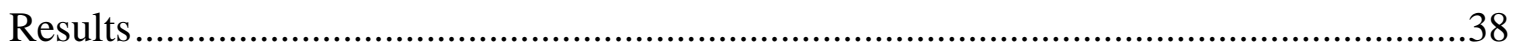

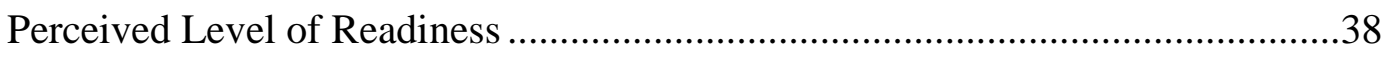

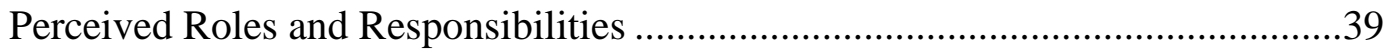

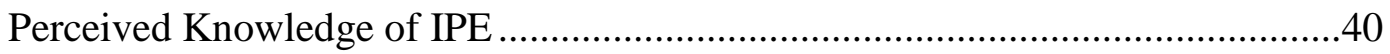

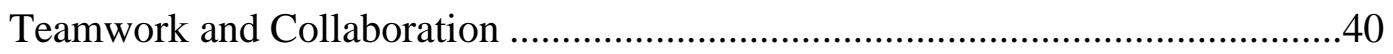

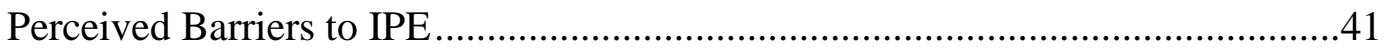

Rank and Role..........................................................................4

Years of Teaching Experience ...........................................................42

Location within the School of Allied Health .........................................44

Previous Experience with IPE ............................................................44

Perceived Skill Level with Using IPE ..............................................44

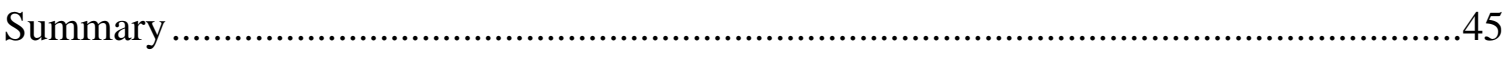

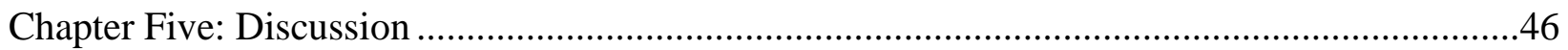

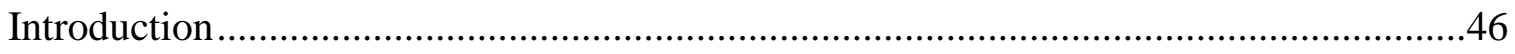

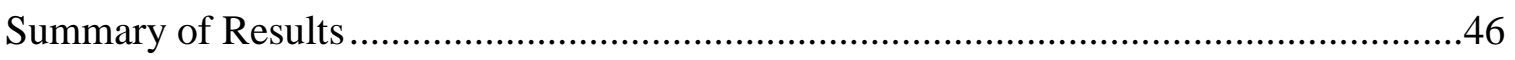

Perceived Level of Readiness ........................................................47

The Effect of IPE Skill Level on Perceptions of IPE.............................48

Perceptions of Interdisciplinary Cooperation ..................................51

Perceived Barriers for IPE ............................................................54

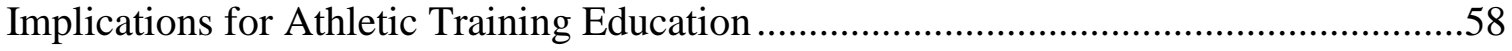

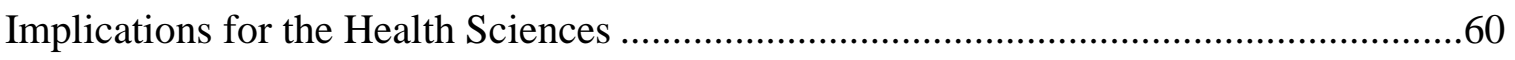

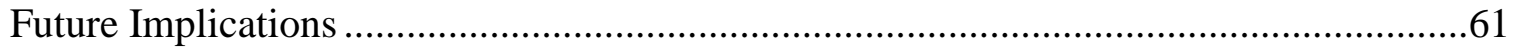

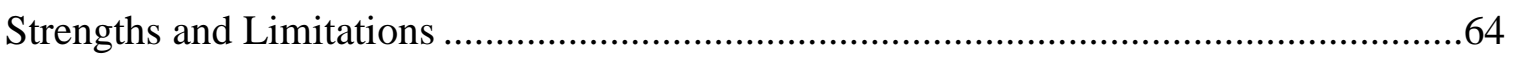

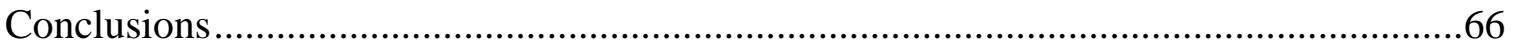

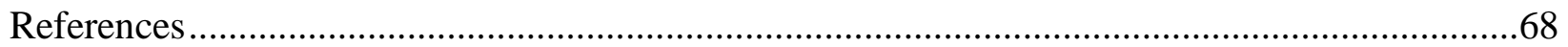

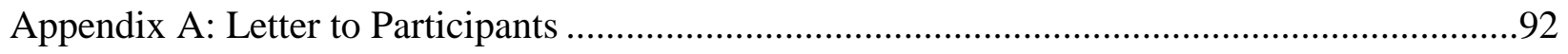

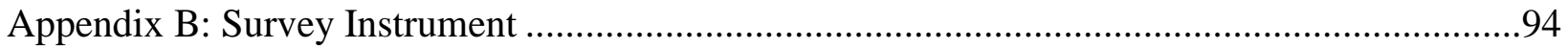




\section{List of Tables}

Table 1 Demographics of Sample (Frequency Distribution)..... .74

Table 2 One-Way ANOVA of Perceived Level of Readiness by Previous Experience with IPE .76

Table 3 One-Way ANOVA of Perceived Roles and Responsibilities by Perceived Skill Level of IPE

Table 4 One-Way ANOVA of Perceived Roles and Responsibilities by Perceived by Independent Variable of Having Previous Experience Teaching with IPE .78

Table 5 One-Way ANOVA of Skill Level of IPE of Perceived Knowledge of IPE .79

Table 6 One-Way ANOVA of ATEP Location on Team Work and Collaboration .80

Table 7 One-Way ANOVA of Independent Variable of Rank or Role on Perceived

Barriers. .81

Table 8 One-Way ANOVA of Independent Variable of Years of Teaching Experience on Perceived Barrier to IP.

Table 9 One-Way ANOVA of Independent Variable of ATEP Location on Perceived

Barriers.

Table 10 One-Way ANOVA of Previous Experience with IPE on Perceived Barriers .84

Table 11 One-Way ANOVA of the Independent Variable of Perceived Skill Level Using IPE on Perceived Barriers .85 


\section{List of Figures}

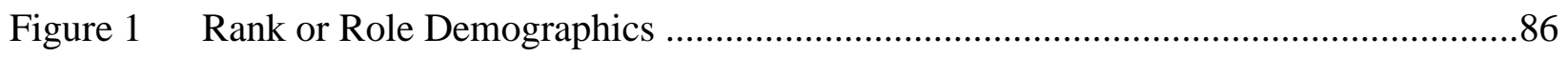

Figure 2 Years of Teaching Experience Demographics ................................................ 87

Figure 3 Perceived Skill Level Using IPE Demographics ................................................8

Figure 4 Independent Variable of Perceived Level of Readiness based on Dependent Variable Previous Experience with Teaching IPE.

Figure 5 Faculty perceived levels of uncertainty regarding roles and responsibilities for interprofessional learning dependent on perceived skill level of using IPE ..............90

Figure 6 Means for lack of leadership as a perceived barrier based on faculty role or role .....91

Figure 7 Means for lack of other allied health disciplines at the institution based on geographical location of ATEP within the institution 


\section{Chapter One: Introduction}

\section{Background of the Study}

The World Health Organization (WHO) recognizes a public need for health care systems and health care education systems to work together to create workforce strategies that best serve the public (Gilbert, Yan, \& Hoffman, 2010). Patients presently face rising healthcare costs, inequities with access to health care and adequate delivery of quality patient care (Ravet, 2012). The WHO suggests collaboration between healthcare education and clinical practices can help address issues within health care systems (Gilbert, Yan, \& Hoffman, 2010). Interprofessional practices (IP) are connected to positive patient outcomes and enhanced learning for students (Zwarenstein, Goldman, \& Reeves, 2009). IP practices implemented within health care education have been associated with nurturing ethically responsible decision-making skills among practitioners (Yarborough, Jones, Cyr, Phillips, \& Stelzner, 2000) and improving interdisciplinary communications among healthcare professionals and among healthcare students (Hagemeier, Hess, Hagen, \& Sorah, 2014). IP practice has also been associated with increasing healthcare professionals' understanding of each other's roles for patient care (Tashiro, Byrne, Kitchen, Vogel, \& Bianco, 2011). The improvements seen in healthcare students and professionals from IP practices has ultimately improved healthcare operations and patient outcomes, which supports the WHO's recognition of interprofessional practices as a public need (Zwarenstein, Goldman \& Reeves, 2009).

Although licensed athletic trainers are allied healthcare professionals who work as members of a healthcare team, there is a lack of evidence demonstrating the use of many interprofessional learning opportunities in current athletic training education programs (Breitbach \& Richardson, 2015). Advocates for the profession recognize this discrepancy and 
are taking initiatives to elevate athletic training education to a status more parallel to other allied healthcare professionals (Breitbach \& Richardson, 2015). The Commission on Accreditation of Athletic Training Education (CAATE) has pronounced a move for athletic training education to transition all entry-level education to professional master's degree programs. This directive, in addition to newly proposed CAATE standards of education for 2017, presents faculty with the challenge of redesigning existing curriculum to reflect these newly imposed standards (CAATE, 2016). Research of allied healthcare education shows that students trained using an interprofessional education (IPE) approach are more likely to: develop into team members who possess a willingness to work collaboratively with other professionals, maintain positive attitudes towards members of other healthcare professions, and strive to work towards an integrated approach to producing positive patient outcomes (Bridges, Davidson, Odegard, Maki, \& Tomkowiak, 2011). The inclusion of athletic training (AT) in IPE experiences could help facilitate the athletic trainer's desire to be recognized and respected as true allied healthcare professionals (Rizzo, 2015).

\section{Statement of the Problem}

Athletic training education is currently lacking a systematic approach to interdisciplinary teaching within its education programs (Breitbach \& Richardson, 2015). Despite the abundance of literature promoting multidisciplinary education in allied health, literature that explores interprofessional approaches in athletic training education is scarce (Tivener and Gloe, 2015). Existing research that has attempted to investigate the use of interprofessional practices in athletic training found that IPE concepts are often misunderstood by athletic training educators (Breitbach \& Richardson, 2015). Although it is recognized that athletic trainers have a place in interprofessional education, AT faculty roles and responsibilities for implementing IPE have not 
been clearly defined (Rizzo et al., 2015). Also, it has yet to be determined what barriers are hindering the implementation of IP practices specifically for athletic training educators. If IPE is going to be effective, faculty must be willing and prepared to implement IPE (Bridges et al., 2011). Therefore, it is important that a study is performed to better understand faculty perceptions of knowledge, beliefs, and barriers related to the implementation IPE in athletic training education programs.

\section{Purpose of the Study}

Abu-Rish, Kim, Choe, Varpio, Malik, White, and Thigpen (2012) identified that there exists a lack of systematic training to prepare faculty for assuming an IPE role in health care education. The specific aim of this study is to provide insight about faculty knowledge and skills regarding IPE and to understand faculty's perceived barriers to implementing IPE in athletic training didactic curriculum. In other allied health professions, gaining an understanding of faculty knowledge, perceptions and perceived barriers for IPE helped identify faculty needs. This was useful in guiding conclusions for developing better strategies for making IPE an integral aspect of allied health education (Abu-Rish et al. 2012; Loversidge \& Demb, 2014; Racine et al., 2016). The CAATE accreditation Standard 14 requires the incorporation of planned interprofessional education on a continuous basis across curriculum (CAATE, 2016). Therefore, in order to stay compliant with accreditation standards, it is necessary that AT faculty have the knowledge and resources to implement IPE into their programs. The logical scientific next step is to address knowledge, perceptions and barriers of IPE for athletic training education, specifically, so that these results can be utilized to help guide faculty development and support programs for IPE within the discipline of athletic training.

The purpose of this study is to provide insight on current faculty knowledge of IPE and 
perceived readiness to implement IPE in AT curriculum. The plan for the results of this

research, is to analyze the current barriers to IPE in athletic training and propose solutions for preparing faculty for the implementation of IPE strategies into their curriculum.

\section{Definition of Terms}

- Interprofessional Education (IPE): the pedagogy of learning with, from and about other disciplines. In reference to healthcare education specifically it has been defined as "any form of health training that emphasizes the team learning of students from a variety of health professions" (Racine, Bilinski, \& Spriggs, 2016, p. 1).

- Interprofessional Practice (IPP): the process of healthcare providers working with other staff and professionals from within their own discipline and with people outside of their discipline.

- The Strategic Alliance: "a group of four leading organizations committed to the athletic training profession and to the delivery of quality healthcare to the public. The four member organizations are the Board of Certification, Inc. (BOC), the Commission on Accreditation of Athletic Training Education (CAATE), the National Athletic Trainers' Association (NATA) and the NATA Research \& Education Foundation (NATA Foundation).” (Joint Statement from the Strategic Alliance, 2015, para. 8)

- Commission on Accreditation of Athletic Training Education (CAATE): the accrediting body for athletic training education. CAATE is "recognized as an accrediting agency by the Council of Higher Education (CHEA)". CAATE's mission is to define, measure, and continually improve AT Education (CAATE, n.d., para. 1).

- ATEP: Athletic Training Education Program

- $A T C$ or AT: Certified Athletic Trainer or Athletic Trainer 
- National Athletic Trainers' Association (NATA): “The professional membership association for certified athletic trainers and others who support the athletic training profession. The mission of the NATA 'is to represent, engage and foster the continued growth and development of the athletic training profession and athletic trainers as unique health care providers.” (NATA, 2017, para. 3)

\section{Assumptions and Delimitations}

Assumptions. It was assumed that faculty demographics such as rank or role, years of teaching experience, and geographic location of an ATEP within their institution have an effect on faculty knowledge, perceptions and perceived barriers to IPE. It was also assumed that the sampling is representative of the population of AT faculty due to the stratified random sampling used to collect subjects for this study. The data was collected voluntarily and anonymously; therefore, it was assumed the participants answered the survey honestly. Participants had the freedom to withdraw their participation at any time and could choose to omit answers to any of the questions and still participate in the study. The researcher assumed the participants already possessed their own definition of IPE and understanding of methodologies for IPE. IPE was not defined for the participants since part of the exploration of this study was to gain insight to the participant's current knowledge of IPE. The nature of the 6 item Likert Scale responses used in this survey assumed that each participant had an opinion that either agreed or disagreed with each item of the survey; there was no option to express a neutral response.

Delimitations. The sample population was purposefully limited to only members of the NATA. However, it is not a requirement for faculty in ATEPs to be a member of the NATA; therefore, it is possible that faculty who currently teach in athletic training programs were not recruited for this study. Also, the dependent variables including age, years of experience, and 
years of clinical experience were collected as categorical data as opposed to continuous data.

This data collection method was purposeful and relates to the planned statistical comparisons; predictive analysis was not planned.

\section{Research Questions}

RQ1: Are AT faculty ready to implement IPE in their programs?

RQ2: What are AT faculty's perceived roles and responsibilities in regards to interprofessional learning?

RQ3: What are AT faculty's perceptions of knowledge of IPE?

RQ4: What are AT faculty's perceptions of teamwork and collaboration as it pertains to education?

RQ5: What are AT faculty's perceived barriers to implementing IPE?

\section{Hypotheses}

Hypothesis 1: Athletic training education program faculty's perceived level of readiness to implement IPE in their programs will increase with higher faculty rank/roles, years of experience teaching, previous experience with IPE, greater perceived skill levels of IPE, and if their ATEP is housed in the school of allied health.

Hypothesis 2: The uncertainty of faculty in athletic training education regarding their roles and responsibilities for interprofessional learning will decrease with more years of experience teaching, higher faculty rank/roles, previous experience with IPE, greater perceived skill levels of IPE, and if their ATEP is housed in the school of allied health.

Hypothesis 3: Faculty perceptions of knowledge of IPE will be influenced by higher faculty rank or role, more years of experience teaching, previous 
experience with IPE, greater perceived skill levels of IPE and if their ATEP is housed in the school of allied health.

Hypothesis 4: Faculty perceptions of teamwork and collaboration will be influenced by higher faculty rank or role, more years of teaching experience, previous experience with IPE, greater perceived skill levels of IPE and if their ATEP is housed in the school of allied health.

Hypothesis 5: Faculty perceptions of barriers to IPE will be influenced by faculty rank or role, years of teaching experience, previous experience using IPE, perceived skill levels of IPE and geographical location of their ATEP within the school of allied health.

\section{Summary}

Considering the new accreditation standards being mandated by CAATE, the call for meaningful research in the area of IPE has never been greater. ATEPs are under timely pressure to design, develop, and implement IPE into their curriculum to maintain accreditation. The aim of this study to explore faculty knowledge and perceptions of IPE and gain an understanding of the perceived barriers to the implementation of IPE within athletic training education. The results of the data analysis are intended to identify the effect of years of teaching experience, faculty rank or role, previous experience with IPE, perceived skill levels of IPE and geographical location of an ATEP within the institution on faculty perceptions of IPE. Ultimately, this study discusses the need for development that addresses the specific needs of faculty of athletic training education programs, especially during this crucial transitional period of athletic training education. Research on IPE for athletic training is timely and necessary for ATEPs as they move toward transition to graduate professional programs in 2022. 


\section{Introduction}

\section{Chapter Two: Review of Literature}

Interprofessional education, by definition, is the pedagogy of learning with, about and from other disciplines. In reference to healthcare education specifically, it has been defined as "any form of health training that emphasizes the team learning of students from a variety of health professions" (Racine, Bilinski, \& Spriggs, 2016, p. 1). IPE provides opportunity for students to reflect critically on their relationship with other members of a healthcare delivery team (Keller, Eggenberger, Belkowitz, Sarsekeyeva \& Zito, 2013; Bridges, et al., 2011). The goal of IPE is to bring disciplines together to gain knowledge about each other's professional roles, obtain clarification about their roles and hopefully achieve a mutual respect for each other's disciplines. The intention is to develop future practitioners prepared to be members of a collaborative practice (Abu-Rish, et al., 2012). IPE emphasizes professional, "responsibility, accountability, coordination, communication, cooperation, assertiveness, autonomy, and mutual trust" (Bridges et al., 2011, p.2). Interdisciplinary education has the ability to encourage healthcare students to honor the boundaries of professional scopes of practice and teaches students how to utilize a team approach to overcome these boundaries in order to deliver optimal patient care (MacNaughton, Chreim \& Bourgeault, 2013). Since literature on IPE is extensive in other allied health professions, the focus here is on literature that supports IPE as a learning pedagogy, the proposed need for IPE due to the evolution of AT education, and the perceived barriers and recommendations for faculty development in the area of IPE.

\section{Review of Pertinent Literature}

IPE Benefits to Education. Interprofessional education activities have the potential to elicit changes in students' attitudes towards IPE and interprofessional practice (IPP) (Reeves et al., 2011). Research has identified a positive correlation with students' attitudes, awareness, and 
knowledge of IPE and its transition to professional practice (Reeves et al., 2011). IPE strategies also promote a transfer of learning from didactical learning to practical application. IPE focuses on problem solving skills in a team setting, and nurtures interprofessional communication skills (Racine et al., 2016). A recent study that evaluated the perceptions of students from general medicine, nursing, and pharmacy after simultaneously participating in an interprofessional communication course found that students from all three disciplines declared improvements in self-confidence in their communication skills (Hagemeier, Hess, Hagen, \& Sorah, 2014).

Another crucial benefit to IPE is the role it plays in achieving a level of awareness in emerging health care professionals; it enhances student understanding of the distinct roles of the diverse health care disciplines (Bridges et al., 2011; Ekmekci, 2013). A simulation case study by Ekmekci (2013), investigated how the integration of interprofessional education into healthcare curriculum can impact collaborative behavior of health care professionals and its particular influence on interprofessional stereotyping. The participants represented the healthcare professions of physicians, registered nurses, physician's assistants, physical therapists, and radiation therapists. The results revealed that the overall tendency for stereotyping among students of different disciplines was significantly lower $(\mathrm{p}<.001)$ for students attending curriculum containing IPE components when compared to students who attended a curriculum without an IPE component (Ekmekci, 2013). Ultimately, Ekmekci (2013) concluded that a greater level of collaboration exists among members of IPE teams, as compared to members of non-IPE healthcare teams and this was considered representative of an enhanced potential for shared leadership among healthcare professionals. IPE's ability to minimize interdisciplinary stereotyping could be an essential link to achieving increased awareness of athletic trainers as healthcare professionals. These benefits of interdisciplinary learning can only be acquired if 
interprofessional teaching strategies are effectively implemented into curriculum; therefore, it is important to explore literature supporting effective IPE for health care professionals.

Efforts for Effective Implementation. For effective implementation, IPE models should be conceptualized, implemented, and assessed for both the classroom and clinical settings. Bridges et al. (2011) made the effort to address best practices for IPE by examining the interprofessional practice models of didactic programs, community-based experiences and interprofessional-simulations. All three models proved to serve the intended goals of IPE but only when critical resources are in place and with the cooperation and commitment of students, faculty and institutional staff. In a systematic review of the effectiveness of IPE delivery strategies in university-based education, clinical practice sites were more impactful to student perceptions of IPE than classroom activities (Lapkin, Levett-Jones, \& Gilligan, 2013). Although classroom based delivery lends the opportunity to educate a large cohort of students concurrently, best transfer of theory to practice occurred in the clinical setting. If classroom based IPE activities are utilized it is suggested these activities be experiential in nature (Lapkin et al., 2013). This experiential approach requires setting a classroom scene that requires students to apply their knowledge and understanding to realistic scenarios. This includes, but is not limited to problem-based case studies, simulations, projects and experiments that address realworld problems (Lapkin et al., 2013). When clinical IP activities are not practical, classroom simulations that are navigated through active, self-directed, problem-based learning are recommended as an efficient replacement (Tivener \& Gloe, 2015; Bridges et al., 2011; Kraemer \& Kahanov, 2014). Since these face-to-face interactive activities require time set aside in the classroom and clinical rotations, the use of technology has also been explored as a resource aiding in IPE implementation (Gray \& Smyth, 2012). 
Using technology to build collaborative online learning communities delivers the benefits of asynchronous communication features that compliments the busy schedules and curriculum of health care education (Gray \& Smyth, 2012). Fan, Radford, \& Fabian (2016) identified the use of mobile-devices among medical students and educators as a popular medium to facilitate learning activities. The use of mobile technology was popular among medical students due to its ease of access to information and how it improved communication between students and educators (Fan et al., 2016). The use of online blogging has also been explored as an instrument for assisting in the interprofessional classroom. Sharing reflective blogs have been reported as a successful tool for medical students to share their experiences with peers, mentors and educators and receive feedback from their educational community (Pinilla et al., 2013). Technology has the ability to facilitate meaningful and targeted discussions that can extend to a large community of learners. As health care education evolves and our learning communities expand interdisciplinarily, the use of technology may prove as a useful tool to aid in the implementation IPE (Pinilla et al., 2013; Fan et al., 2016; Gray \& Smyth, 2012).

The Evolution of Athletic Training Education. In the realm of sports medicine, athletic trainers (ATs) are well known for their significant role as the primary care providers for the physically active population. Patients often present with comorbid health care needs that require a multidisciplinary, team approach to address the issues regarding their health status (Bridges et al., 2011). Athletic trainers are typically the first line of defense of an athlete's health care (Rizzo, Breitbach \& Richardson, 2015). They are an athlete's advocate for referral, treatment, rehabilitation, and prevention of illness and injury (Rizzo et al., 2015). A critical characteristic of an athletic trainer's responsibility is the ability to collaborate with physicians, physical therapists, nurses, nutritionists, mental health specialists and other healthcare 
professionals to provide optimum care for their patients (Rizzo et al., 2015). The athletic trainer is the individual responsible for advocating for their patients when communication is needed with other healthcare professionals (Rizzo et al., 2015). Despite the critical role athletic trainers currently have for patient care, the AT profession is still working towards a higher level of awareness as allied health care professionals.

Per the Joint Statement from the Strategic Alliance (2015), physicians consider ATs to be integral members of the interprofessional healthcare team; however, amidst the broad jurisdiction of healthcare, ATs are still searching for acceptance. The research conducted by the Strategic Alliance has identified interprofessional education as the critical link to the acceptance of ATs in the healthcare arena (Joint Statement from the Strategic Alliance, 2015). Therefore, with the best interests of the AT profession in mind, the AT Strategic Alliance announced the professional degree in athletic training will exist at the minimum of a master's degree as of the year 2022 (Joint Statement from the Strategic Alliance, 2015). This decision was made in attempt to better align the discipline of athletic training with other licensed allied health care professionals. Complimentary professionals such as, physician's assistants, physical therapists and occupational therapists, all have professional degrees at a master's level or higher. The scope and role for athletic trainers has been rapidly expanding as the nature of sport and healthcare has evolved. Athletic trainers serve a primary care role for patients that involves injury prevention, emergency care, clinical diagnosis, therapeutic intervention and rehabilitation of a wide range of medical conditions (Rizzo et al., 2015). The traditional patient of an athletic trainer has expanded from athletes, to military personnel, the performing arts, geriatrics, and patients with non-sport-related orthopedic conditions (Rizzo et al., 2015). ATs are using their skills and expertise to contribute to improving patient outcomes in urban hospitals, emergency 
rooms, occupational health departments and even the commercial sector (Rizzo et al., 2015). As our healthcare and higher education systems also continue to rapidly transform, "change [for the AT profession] is not only inevitable, but necessary." (Joint Statement from the Strategic Alliance, 2015, para. 4).

IPE and AT Education. As ATEPs prepare for the transition from bachelor to master's degree programs, the necessary incorporation of IPE becomes even more apparent (Joint Statement from the Strategic Alliance, 2015). It is common knowledge that ATs working in the field apply IPP on almost a daily basis and research in healthcare education has already established support for IPE within healthcare education (Rizzo, 2015). However, current literature possesses a gap in the representation of IPE specific to AT education (Abu-Rish et al, 2012). As for athletic training education, existing literature on IPE consists mostly of reports of student attitudes and perceptions of IPE experiences, or attempts to convey interdisciplinary practices for athletic training by replicating reported practices performed by other allied health education programs (Kraemer and Kahanov, 2014). IPE programs are most successfully implemented when they are tailored to the learning needs of the specific discipline; therefore, it is imperative that specific educational barriers for AT are identified rather than assuming AT faces the same challenges of other allied health education programs (Racine et al., 2016). There is a lack of literature supporting a grassroots approach to defining what steps need to be taken to progress AT students into the educational framework of other disciplines of primary care that athletic trainers associate with professionally (Breitbach \& Richardson, 2015).

Due to the lack of evidence supporting the integration of AT students and students in other health professions, Breitbach \& Cuppett (2012) investigated the incorporation of AT into already established healthcare IPE programs. The researchers discussed how nurturing 
interprofessional collaboration early in education, provides healthcare students of all disciplines the opportunity to adapt early to the socialization of interprofessional practice. The researchers also discussed how early implementation of IPE in AT education provides the opportunity for AT students to validate their roles as an important member of the healthcare team to their peers. Ultimately, these benefits could aid in facilitating AT's recognition as a true healthcare profession (Breitbach \& Cuppett, 2012). Breitbach recognized the need to further address the effects of IPE on the profession of AT; therefore, he further continued with research. Breitbach \& Richardson (2015) collaborated to create a directive paper regarding the existing literature on IPE and the potential transferability of these applications to athletic training education. Perceived benefits and barriers for AT were concluded based on the results of existing literature on IPE in healthcare education (Breitbach \& Richardson, 2015); however, research providing feedback from AT faculty is still needed.

Barriers to IPE. Literature supports the need for early integration of IPE into the AT educational process (Breitbach \& Richardson, 2015; Rizzo et al., 2015). Nonetheless, it is important to highlight that with the many benefits of IPE, there exist many potential challenges to its implementation. Literature indicates challenges exist regarding the roles and responsibilities of faculty and administrators, access to adequate resources needed for designing and maintaining IPE programs, and adequate time for the execution of interdisciplinary education (Abu-Rish et al., 2012; Racine et al., 2016; Sanborn, 2016; Loversidge \& Demb, 2015). Abu-Rish et al., (2012) conducted a systematic review of literature that addressed aspects affecting interprofessional education in health care. Seventy-eight percent of the articles identified barriers to IPE implementation that were specific to demands imposed on faculty. Faculty limitations for IPE implementation extend from altering or designing curriculum content, 
course scheduling, faculty workloads, administrative support, and insufficient funding (Abu-Rish et al., 2012; Loversidge \& Demb, 2015). Redesigning courses to embed IPE strategies often requires critical resources and extraordinary time and effort beyond established faculty responsibilities (Loversidge and Demb, 2015). Institutions have faced major constraints such as scheduling restrictions, insufficient personnel, lack of technological resources, inadequate physical space, and time for curricular planning (Lapkin et al., 2013; Bridges et al., 2011; Loversidge and Demb, 2015). In some cases, acquiring the knowledge and skills for implementing IPE expanded as far as needing faculty release time for IPE professional development (Abu-Rish, et.al., 2012). The majority of evidence identifies scheduling as the most recurrent reported barrier to IPE implementation (Abu-Rish et al., 2012). Additionally, those programs who initiated IPE involving multiple disciplines within their institution reported issues with collaboration of academic calendars, curricular mapping, and managing large student cohorts (Lapkin et al., 2013). Faculty also face apparent disparities between undergraduate and graduate level resources. There are reported challenges with matching students with compatible knowledge and skill levels which poses a problem with setting up clinical simulations that foster learning for all (Abu-Rish et al., 2012).

Many institutions fail to recognize interprofessional teaching load in promotion, rank, and tenure processes. Faculty motivation to implement IPE is greater when adequate engagement and support from their administrative leadership is provided (Breitbach \& Richardson, 2015). Faculty battle with a lack of time available for IPE courses in crowded curricular tracks, and struggle to recruit adequate personnel for the planning and organization of IPE activities (Abu-Rish et al., 2012). When collaborating with other disciplines, faculty have also reported issues regarding misconceptions about interdisciplinary roles and responsibilities a 
midst faculty members (Breitbach, \& Richardson, 2015). Faculty express that these barriers seem to place the burden of IPE implementation solely on themselves (Breitbach, \& Richardson, 2015).

Faculty also report having no formal training in pedagogies specific to the facilitation and practice of activities for teamwork and interprofessional collaboration (Breitbach, \& Richardson, 2015). Evidence demonstrates effective implementation of IPE is dependent on formal faculty training and appropriate administrative and institutional support (Loversidge \& Demb, 2015). It is important to note that most of these studies investigated IPE across disciplines such as medical, nursing, dentistry, and pharmacology (Abu-Rish et al., 2012; Loversidge \& Demb, 2015). The results can foreseeably be transferred to other healthcare disciplines such as athletic training. However, further research directed towards athletic training education is needed to address what specific needs and constraints are present when integrating IPE for athletic trainers (Breitbach, \& Richardson, 2015).

Faculty Needs. When faculty were asked what they needed to overcome these perceived barriers, they recommended appropriate mentoring, training sessions and commitment from faculty and staff of all departments and colleges involved (Bridges et al., 2011). Successful implementation of IPE relies heavily on the proper training and support for faculty (Abu-Rish et al., 2012; Loversidge \& Demb, 2015). Abu-Rish et al. (2012) found that $81.9 \%$ of faculty who reported having IPE skills could not describe where they acquired their IPE skills. Despite all the literature on IPE for professional healthcare education, evidence of IP initiatives specific for AT faculty is rather scarce (Rizzo et al., 2015). There is an inherent need for faculty training sessions to introduce procedures that help facilitate IPE interactions and help make IPE a sustainable notion in healthcare education (Abu-Rish et al., 2012). Abu-Rish et al. (2012) 
identified a need for faculty workshops and mentoring programs that focus specifically on IPE skill-building both didactically and clinically. An Interprofessional Education Development Model (IPEDM) currently exists to provide ATEPs with guidelines for coordinating IPE into their curriculum; however, preliminary data on faculty perceptions, knowledge, and readiness to implement IPE in athletic training is lacking (Kraemer and Kahanov, 2014). The current recommendations of the IPEDM are based off IPE research across the broad spectrum of healthcare education therefore, are non-specific to AT education (Kraemer and Kahanov, 2014). In addition to adequate training for faculty, support from institutional leadership members and financial support are also major needs for the sustainability of a successful IPE program (AbuRish et al., 2012). Negative perspectives of IPE are generally a reflection of the absence of a support system for faculty (Abu-Rish et al., 2012). A lack of institutional support places the development of IPE programs completely on the faculty, when ideally it should be a community effort involving students, staff, patients and families as co-developers (Abu-Rish et al., 2012).

The review of IPE literature by Abu-Rish et al. (2012) ultimately concluded that more research on faculty knowledge and perceptions towards IPE is necessary to determine specific needs for implementing faculty developmental programs. Racine et al. (2016) also recognized this need to better understand faculty perceptions of IPE and therefore, conducted a pilot study specific to nursing faculty's knowledge, skills, and readiness to apply IPE to their teaching. The study aimed to identify faculty's current knowledge of IPE pedagogy, gain an understanding of individual and institutional barriers that faculty face, and ultimately to define specific needs for faculty development (Racine et al., 2016). Overall, the findings revealed that faculty agree that IPE is vital for enhancing team-working skills; however, they expressed time, heavy workloads and space in the existing curricula as major barriers to implementation (Racine et al., 2016). The 
majority (70\%) of participants were in support of IPE learning needs to be met through a workshop; however, setting a timetable for conducting such a workshop presented an additional barrier (Racine et al., 2016).

Racine et al. (2016) research results inspired the research objectives for this study aimed towards athletic training faculty. The implementation of IPE in nursing and other healthcare disciplines has been addressed in literature for over 15 years. Despite the extensive research, faculty teaching IPE in healthcare still express a need for instructional support (Racine et al., 2016). As the athletic training profession makes progress toward the next level as an allied health care profession, IPE proposes strategies for preparing future certified athletic trainers for their role as an integral member of the health care team (Rizzo et al., 2015). To provide proper guidance for effective implementation of IPE in ATEPs, further exploration of the attitudes and perceptions of AT faculty should occur (Rizzo et al., 2015; Breitbach \& Richardson, 2015). It is recognizable that appropriate faculty training transfers to the success of IPE programs (Kraemer \& Kahanov, 2014). Knowledge gained from a study of AT faculty perceptions of IPE can be useful to provide recommendations for faculty, preceptors, and students in how to prepare for IPE implementation (Rizzo et al., 2015).

\section{Conceptual Framework}

The theoretical framework of cooperative, collaborative, social, experiential learning forms the basis for IPE (Caswell \& Gould, 2008). Theories of IPE express that one discipline may contribute a resource that another may lack and together they form a comprehensive set of resources (Welsh, Rutledge, \& Hoch, 2017). Outcomes of interprofessional education indicate that combining resources across disciplines can broaden the opportunity for student success (Caswell \& Gould, 2008). 


\section{Summary}

The Fifth Edition of the National Athletic Training Association's (NATA) Athletic Training Education Competencies (ATEC) indicates that professional practice behaviors should be nurtured through a team approach and ATEPs are held accountable for implementing strategies for teaching their students to practice as team (Kraemer \& Kahanov, 2014). Studies on IPE frameworks have provided insight regarding the responsibilities and resources needed for designing and maintaining IPE programs in healthcare education (Abu-Rish et al., 2012; Loversidge \& Demb, 2015; Bridges et al., 2011). Research has revealed that executing interdisciplinary education requires extraordinary time and effort customary to faculty obligations which often requires additional funding and possible release time for professional development. It is recognizable that appropriate faculty training transfers to the success of IPE programs (Kraemer \& Kahanov, 2014). Despite extensive research on IPE, there remains the question, of how sufficient faculty training can be developed without an understanding of faculty knowledge and perceptions of IPE (Rizzo et al., 2015; Breitbach \& Richardson, 2015). In order to understand the needs of faculty in AT, it would be beneficial to explore AT faculty's current perceived level of readiness, perceived knowledge, perceived roles and responsibilities, perceptions of teamwork and collaboration and barriers to implementing IPE (Rizzo et al., 2015; Breitbach \& Richardson, 2015). 


\section{Introduction}

\section{Chapter Three: Methodology}

The research methods for this study were adopted, with permission, from: Racine, L., Bilinski, H., \& Spriggs. (2016). Nursing Faculty's Needs of Knowledge, Beliefs, and Readiness to Implement Interprofessional Education in their Teaching: An Exploratory Study. Quality Advancement in Nursing Education - Avancées en formation infirmière. 2(1), 1-19. This study focused on gaining insight of faculty perceived knowledge and readiness to implement IPE, with aims for identifying barriers and needs for overcoming these barriers.

\section{Review of the Purpose of the Study}

The purpose of this study was to obtain insight on current faculty's perceived knowledge of IPE, perceived readiness, perceived role and responsibilities, and perceptions of teamwork and collaboration, with aims for identifying barriers and needs for overcoming these barriers. The results were analyzed to explore if differences in faculty perceptions are affected by faculty demographics such as rank or role, years of teaching experience, previous experience with IPE, perceived skill level with using IPE and geographical location of athletic training education programs in relation to other healthcare disciplines within the institution. These results were further interpreted to see what barriers hinder AT faculty from implementing IPE strategies in their curriculum.

\section{Specific Description of the Methodology}

An electronic survey, using SurveyMonkey, was distributed to 1000 athletic training education program (ATEP) faculty members by means of the NATA's member mailing list. As per standard procedure, the NATA agreed to distribute the survey on the researcher's behalf. The survey responses were returned to the researcher without IP address identifiers to ensure anonymity of the participants. 


\section{Research Design of the Study}

The research design of this study was survey research with stratified, random sampling from a database of NATA members. The direction of the survey was to investigate faculty perceptions of IPE for the discipline of athletic training. An electronic survey was used to collect quantitative responses using a standard 6-point Likert Scale. The survey items were categorized to address each of the research questions and their correlated hypotheses. Each quantitative section of the survey had a qualitative aspect that allowed participants to elaborate and give explanations for their Likert Scale rankings. The data analysis examined for effects of the independent variables on the responses to each research question. Descriptive and parametric statistical analyses were used to explore any significant differences between faculty rank or role, years of experience teaching, previous experience with IPE, perceived skill level with using IPE and geographical location of the ATEP within the institution on the perceived level of knowledge, roles and responsibilities, perceptions of teamwork and collaboration, perceived readiness and perceived barriers of AT faculty on IPE.

\section{Sample, Population, and Source of Data}

The sample consisted of a stratified random sample from 1000 NATA members who indicate an educator status in their membership profile. The sample included NATA members from all ten-districts across the United States. A total of 189 faculty submitted their responses to the Readiness to Implement Interprofessional Education in Athletic Training Survey.

\section{Inclusion Criteria}

To be included in the study, participants must be an educator in an athletic training education program (ATEP) and an NATA member. All faculty in ATEPs were welcomed to participate despite status at their institution including, but not limited to, rank or role, tenure 
track, full-time/part-time, clinical instructors, adjuncts, clinical coordinators, and program directors. Clinical preceptors were included if they had a teaching role in the ATEP.

\section{Exclusion Criteria}

Exclusion criteria included retired faculty, emeritus status, or any NATA members whose role as an educator in an ATEP is solely as a clinical preceptor.

\section{Instrumentation}

The survey was comprised of 56 items; 9 demographic questions and 47 questions on faculty knowledge, perceptions, and barriers to IPE (See Appendix A). The phrasing of the survey items derived from the Interdisciplinary Education Perception Scale were preserved as adopted from Luecht et al. (1990). Most survey items asked participants to indicate their level of agreement on a 6-point Likert scale $(1=$ strongly disagree; 2 = moderately disagree; $3=$ somewhat disagree; $4=$ somewhat agree; $5=$ moderately agree; $6=$ strongly agree. Other items asked participants to respond to open-ended questions or to respond simply 'yes' or 'no'. Racine, et al. (2016) do not possess ownership over the survey instrument used for their study. The survey questions utilized in Racine et al.'s work, as well as the research presented here, were derived from two validated and reliable instruments: The National Competency Framework (Canadian Interprofessional Health Collaborative [CIHC], 2010) and the Interdisciplinary Education Perception Scale (IEPS) (McFadyen et al., 2007). The National Competency Framework and the IEPS are both free and readily available for public use. Racine et al. (2016) confirmed the face validity, content validity, and internal consistency by use of a Cronbach's alpha of .943; the authors claimed that this suggested "high homogeneity among the total item in measuring domains of IPE.” (p. 5) The psychometric properties of the original IEPS were reported by Luecht, Madsen, Taugher, and Petterson in 1990. Luecht et al. (1990) reported 
internal consistency values for each sub-scale of the instrument. The original IEPS consists of 4 subscales: Competency and Autonomy, Perceived Need for Cooperation, Perception of Actual Cooperation, and Understanding Others' Value. Using a Cronbach's Alpha the IEPS in its entirety earned an alpha value of 0.872 sub-scale with each subscale receiving individual values of $0.823,0.563,0.543$ and 0.518 respectively (Luecht et al., 1990). The content of the IEPS was identified as more appropriate for assessing attitudes in regards to professional collaboration and the assessment of more advanced students (Lie, Fung, Trial, \& Lohenry, 2013). As a result, the IEPS was chosen for this study over other valid instruments designed to assess perceptions of IPE such as the Readiness for Interprofessional Learning Scale (RIPLS) (Lie et al., 2013).

\section{Dependent Variables}

The dependent variables included the following: faculty perception of knowledge, perceived level of readiness, perceived roles and responsibilities, perceptions of teamwork and collaboration, and perceived barriers to IPE.

\section{Independent Variables}

The independent variables for this study include the following: faculty rank or role, years of experience teaching, previous experience with IPE, perceived skill level with using IPE and if the faculty member's ATEP was housed in the school or college of allied health at their institution.

\section{Informed Consent Process}

The online distribution of the survey allowed the participants' identities to remain anonymous. Participation in the study was voluntary and was indicated in an introductory letter to the participants. Since the NATA distributed the survey on the researcher's behalf, it was required to adopt the "NATA Sample Cover Letter for Student Surveys" (See Appendix B). 
Details of informed consent were also included as part of this introductory letter. The letter specified that by submitting a completed survey the subject was giving their informed consent for utilization of their responses. There was no incentive presented to the participants of this study other than acknowledging that their input would be used to gain an understanding of how faculty training programs can be constructed to support IPE strategies for athletic training. A follow up email was sent to all participants two weeks after the original invitation to remind nonrespondents of the request of their participation in the survey.

\section{Statistical Analysis}

IBM SPSS Statistics software was used for all statistical analysis of data. The data analysis explored the effects of the independent variables on faculty perception of knowledge, perceived level of readiness, perceived roles and responsibilities, perceptions of teamwork and collaboration, and perceived barriers to IPE. Descriptive and parametric statistical analyses were used to explore differences between faculty rank or role, years of experience teaching, previous experience with IPE, perceived skill level with IPE and geographical location of the ATEP within the college of health sciences and the perceived knowledge, readiness and barriers for implementing IPE in AT education programs. An ANOVA was used to compare the difference between means of each research question. Research questions were answered by an individual survey item response, while others were answered by a grand mean of questions that all belong within a specific designated category.

Historically, Likert scale responses have been considered ordinal data which would make them more appropriate for non-parametric statistics. Using parametric statistics assumes that the Likert responses exist as integral data; meaning that the difference between 1 and 2 and 2 and 3 is an equal distance with a specific value. Some literature suggests not to assume that there is 
consistency between the ratings with Likert scales; however, the decision was made to run the data parametrically as the simplicity of non-parametric tests hold less appeal when compared to parametric analyses (Bishop \& Herron, 2015).

The Likert style tool used for this study had a 6-point scale and no neutral option, eliminating balance as an issue. There were equal options for "Disagree" and equal options of "Agree". A rating of 6 was a highly positive response to the survey item questions. By using a 6-point, balanced Likert with no "neutral" ranking, it was assumed that differences between "somewhat agree" and "moderately agree" and "moderately agree" and "strongly agree" are equal values; therefore, referring to the Likert responses as integral data and supporting the use of an ANOVA (Bishop \& Herron, 2015).

Studies done by Carifio \& Perla (2007) provided empirical evidence that Likert responses are representative of linear and interval data. Carifio \& Perla (2007) compared responses to the same set of questions, with one group of responses using an anchored Likert scale, and the other group using the traditional Likert response format. The results presented a high level of correlation between the two response methods suggesting that Likert responses are equivalent to scaled data. This evidence supports the use of Likert responses as interval data in ANOVA analyses.

Even more supportive evidence of Likert data as integral data, is the idea of Likert groups versus items. Evidence supports analyzing data from Likert scales parametrically if more than a single Likert item is being analyzed (Carifio \& Perla, 2007). Likert items analyzed alone do not share the same properties compared to when the responses are appropriately grouped. When a group of Likert responses is linked into a related group of questions, the logical and empirical properties of the individual constituents weighted among the items comprising the group, giving 
it more complex meaning, and a scale emerges from the group. To clarify, the atom analogy is used to describe this theory. Sometimes individual atoms do not appear to be very robust when they stand alone, however, when properly arranged, a group of atoms creates a molecule with distinct measurable characteristics. This supports the summation of grouped Likert item responses using means and standard deviations and analyzing them parametrically using univariate and multivariate techniques (Carifio \& Perla, 2007). For this reason, the dependent variables used to answer the research questions for this study were derived from the delineated subscales of the IEPS (Luecht et al, 1990). The four subscales of the IEPS are: Competency and Autonomy, Perceived Need for Cooperation, Perception of Actual Cooperation, and Understanding Others' Value (Luecht et al, 1990).

\section{Summary}

The purpose of this study is to provide quantitative data regarding current faculty perceptions of knowledge, perceived level of readiness, perceived roles and responsibilities, perceptions of teamwork and collaboration, and perceived barriers to IPE. This study used an electronically distributed survey to sample faculty in ATEPs nationwide by utilizing the NATA's member e-mail distribution list. By collecting demographic data such as faculty rank and roles, years of experience, previous experience with IPE, perceived skill level with using IPE and the geographical location of the ATEP in relation to the college of health sciences, the researcher was able to explore independent variables that may affect faculty perceptions of IPE. The results of this research identified the current barriers to IPE among athletic training faculty and explored the effect of demographic variables on these perceived barriers. Ultimately, the intent of the data was to identify faculty needs for implementing IPE strategies in athletic training education curriculum. The results of this study may lead to further exploration of IPE for athletic training 
educational programs and provide recommendations that will aid faculty in transitioning their programs to meet the newly proposed CAATE accreditation requirements 


\section{Chapter Four: Analysis of Data}

\section{Introduction}

This study investigated five major research questions aimed at identifying faculty's perceived knowledge, readiness and barriers for implementing IPE in an AT curriculum. The survey instrument, as adopted from Racine, Bilinski and Spriggs (2016), consisted of survey items directly from the Interdisciplinary Education Perception Scale (IEPS) and additional items were derived from The National Competency Framework (CIHC, 2010). The IEPS survey items are categorized by four subheadings: competency and autonomy, perception of actual cooperation, perceived need for cooperation, and understanding other's values. The additional survey items inspired by The National Competency Framework were categorized under the subheading of Perceptions of IPE and a list of perceived barriers to be rated on a Likert scale of 1-6 were also included in the instrument (Racine et al., 2016) and were analyzed as a subheading of their own, and as individual items.

\section{Use of Statistical Analysis}

The data collected for the purpose of this research was quantitative in nature, with the support of a few open-ended questions to help explain the participants' responses. The participants' demographics were collected quantitatively and served as categorical variables that were used for comparison against the dependent variables in the ANOVA. A one-way between subjects ANOVA was conducted to compare the effect of faculty rank or role, years of teaching experience, previous experience with IPE, perceived skill level with using IPE and location of their ATEP at the institution, on faculty perceptions of readiness to implement IPE. Faculty perceptions that were explored were regarding knowledge, level of perceived readiness, roles and responsibilities, colleague cooperation and barriers to implementing IPE. 


\section{Assumptions}

Before conducting the ANOVA, the assumptions for this test were assessed. The dependent variables were measured using Likert Scale responses on a grading scale of 1-6. According to Bishop and Herron (2015), Likert scale responses on a scale of more than 5, with no neutral option, is acceptable to be considered integral data. The independent variables all consist of two or more categorical groups, meeting this ANOVA assumption. The data collected was randomly and independently sampled and all conditions for each dependent variable were independent of one another. There were no significant outliers identified with any of the dependent variables. Due to its high reliability for avoiding Type I and Type II errors, the nonparametric Levene's test was conducted for each research question to determine equal variances. The results for each Levene's test were reported with each ANOVA results along with Tukey post hoc comparisons, as needed. The Tukey HSD (honest significant difference) post hoc was chosen based on its ability to distinguish where statistical significance exists between multiple variables by using the mean difference. Unlike other post hoc tests, the Tukey is robust in situations of multiple comparisons, as a result, the Tukey was chosen over other post hoc comparisons due to its power and sensitivity for identifying significance (Keppel \& Wickens, 2004).

In some cases, the assumption of homogeneity was violated per Levene's test. However, due to the robust nature of the ANOVA for tolerating violations to its assumptions, when this situation presented, a Gabrielle and Games-Howell post-hoc was conducted to account for unequal variance and/or unequal size group. The results of the Gabrielle and Games-Howell post-hoc were compared to the Tukey; when the second post hoc yielded the same areas of significance, the results for the Tukey remained in the analysis report (Keppel \& Wickens, 
2004).

\section{Demographics}

A total of 189 faculty submitted their responses to the Readiness to Implement Interprofessional Education in Athletic Training Survey and were categorized by the demographics of rank or role (see Table 1; Figure 1), years of teaching experience (see Table 1; Figure 2), previous experience with IPE (see Table 1), perceived skill level with using IPE (see Table 1; Figure 3), and geographical location of the ATEP with the institution (see Table 1).

\section{Results}

Perceived Level of Readiness. The first research question explored faculty's perceived level of readiness to implement IPE in their AT programs against their demographic characteristics. It was hypothesized that faculty's perceived level of readiness to implement IPE in their programs is dependent on factors such as faculty rank or role, years of experience teaching, previous experience with IPE or if their ATEP is housed in the school of allied health. Faculty reported their perceived level of readiness on a Likert scale of 1-6; a score of 1 was identified as Not Ready at All and a score of 6 indicated Extremely Ready.

In the analysis of perceived level of readiness, significance was found between faculty with previous experience with IPE, however, the Levene's test for homogeneity was not met $[\mathrm{F}(2,144)=3.97, \mathrm{p}=.02]$. Therefore, the Welch's ANOVA was examined for significance. There was a significant effect of previous experience on perceived readiness for IPE at the $\mathrm{p}<.05$ level $[\mathrm{F}(2,144)=19.92, \mathrm{p}=.00]$ (see Table 2$)$. The Tukey HSD post hoc comparison indicated that the mean score for faculty without previous IPE experience $(\mathrm{M}=3.01, \mathrm{SD}=1.14)$ was significantly lower than faculty with previous IPE experience $(M=4.01, S D=0.80)$ (see Figure 4). 
Perceived Roles and Responsibilities. The second research question investigated faculty's perceived roles and responsibilities in regards to interprofessional learning. It was hypothesized that the uncertainty of faculty in athletic training regarding roles and responsibilities for interprofessional learning is dependent on factors such as, as faculty rank or role, years of teaching experience, previous experience with IPE or the geographical location of their ATEP within their institution.

In the analysis of perceived roles and responsibilities, significance was found among perceived skill level and previous experience. In the comparison of the independent variable of perceived skill level, the Levene's test for homogeneity was not met $[F(4,155)=3.83, p=.00]$ so the researcher referred to the Welch's ANOVA which was significant at the $p<.05$ level $[F(4$, $155)=31.63, \mathrm{p}=.00]$ (See Table 3$)$. The Games-Howell post-hoc identified faculty who reported having No Skills in IPE $(\mathrm{M}=5.33, \mathrm{SD}=1.11)$ rated their uncertainty significantly higher than those who identify with having Few IPE Skills $(\mathrm{M}=3.56, \mathrm{SD}=1.09)$ and both of these groups rated their uncertainty significantly higher than those with a Moderate Skill Level $(M=2.48, S D=1.06)$ and all were significantly more uncertain than those with quite a bit of IPE skills $(\mathrm{M}=1.76, \mathrm{SD}=0.76)$. Those who rated their skills as Proficient $(\mathrm{M}=2.40, \mathrm{SD}=$ 2.19) had no significant difference when compared with all other skill levels (see Figure 5).

The analysis of perceived roles and responsibilities, also revealed a significant difference between faculty with no previous experience and faculty with IPE experience at the $p<.05$ level $[\mathrm{F}(2,158)=38.28, \mathrm{p}=.00]($ see Table 4$)$. The assumption of homogeneity was not met with a Levene's of $[\mathrm{F}(2,158)=4.71, \mathrm{p}=.01]$. However, significance was confirmed with the GamesHowell, identifying faculty with no previous experience rated their level of uncertainty with their role in IPE significantly higher $(\mathrm{M}=3.68, \mathrm{SD}=1.44)$ than faculty with previous IPE experience 
$(\mathrm{M}=2.30, \mathrm{SD}=1.07)$

Perceived Knowledge of IPE. The third research question explored faculty knowledge about IPE. It was anticipated that faculty perceptions of knowledge of IPE would be dependent on factors such as, faculty rank or role, years of teaching experience, previous experience with IPE, perceived skill levels of IPE and where the ATEP is housed within the institution. Faculty perceived knowledge of IPE was identified by their responses to survey items under the subcategory of autonomy and competency. In the analysis of faculty's perceived knowledge of IPE, all ANOVA assumptions were met and significance was found among faculty with different perceived levels of IPE skills; all other independent variables showed no significant difference for perceived knowledge of IPE.

There was a significant effect of perceived level of IPE skills on competency and autonomy at the $\mathrm{p}<.05$ level $[\mathrm{F}(4,154)=4.70, \mathrm{p}=.001]$ (see Table 5). A Tukey HSD post hoc comparison indicated that the mean score for faculty who identified with having proficient skills for using IPE $(\mathrm{M}=3.37, \mathrm{SD}=0.86)$ was significantly different than the groups who identified with having a moderate amount of IPE skills $(\mathrm{M}=4.43, \mathrm{SD}=0.59)$, a few IPE skills $(\mathrm{M}=4.26$, $\mathrm{SD}=0.63)$, and no IPE skills $(\mathrm{M}=4.69, \mathrm{SD}=0.95)$.

Teamwork and Collaboration. The fourth research question addressed faculty perceptions of teamwork and collaboration as it pertains to IPE. The researcher hypothesized that faculty perceptions of teamwork and collaboration would be dependent on factors such as, years of teaching experience, faculty rank or role, previous experience with IPE, perceived skill levels of IPE and where the ATEP is housed within the institution. A one-way between subjects ANOVA was conducted to compare the effect of faculty rank or role, years of teaching experience, location of their ATEP within the institution, previous experience using IPE, and 
frequency using IPE on the survey subcategories of Actual Cooperation and the Need for

\section{Cooperation.}

There was a significant effect of geographical location of the ATEP within the institution on actual cooperation at the $\mathrm{p}<.05$ level $[\mathrm{F}(2,149)=3.27, \mathrm{p}=0.04]$ (see Table 6). All assumptions of the ANOVA were met. The ANOVA indicated that the mean score for not having an ATEP housed in the division of allied health $(\mathrm{M}=4.62, \mathrm{SD}=0.58)$ was significantly different than those faculty having ATEPs housed within their school of allied health $(\mathrm{M}=4.37$, $\mathrm{SD}=0.64)$

Perceived Barriers to IPE. The final research question in this study explored faculty perceptions of barriers for implementing IPE. It was hypothesized that perceptions of barriers would be dependent on faculty rank or role, years of teaching experience, previous experience using IPE, perceived skill levels of IPE and geographical location of their ATEP within the school of allied health.

Rank and Role. There was a significant effect of faculty rank or role on lack of leadership as a perceived barrier at the $\mathrm{p}<.05$ level $[\mathrm{F}(8,134)=2.342, \mathrm{p}=0.23]$ (see Table 7). Post hoc comparisons using the Tukey HSD indicated that the mean score for the rank of professor $(\mathrm{M}=2.65, \mathrm{SD}=1.43)$ was significantly different than the rank of clinical instructor $(\mathrm{M}$ $=4.50, \mathrm{SD}=1.41)($ see Figure 6$)$. However, there was no significant difference between any of the other rank or roles for the perceived barrier of lack of leadership.

There was a significant effect of faculty rank or role on political tension as a perceived barrier at the $\mathrm{p}<.05$ level $[\mathrm{F}(8,134)=2.32, \mathrm{p}=0.02]$ (see Table 7). Levene's test of homogeneity was not met $[\mathrm{F}(8,134)=2.06, \mathrm{p}=.04]$, and the Games-Howell identified additional significant differences compared to the Tukey HSD, so the Games-Howell results 
were reported. A Games-Howell post-hoc test indicated that clinical instructors $(\mathrm{M}=5.25, \mathrm{SD}=$ 0.70) rated political tension significantly higher than program directors $(\mathrm{M}-3.52, \mathrm{SD}=1.43$ ), clinical coordinators $(\mathrm{M}=3.08, \mathrm{SD}=1.38)$, professors $(\mathrm{M}=3.70, \mathrm{SD}=1.52)$ and assistant professors $(\mathrm{M}=3.54, \mathrm{SD}=1.44)$.

There was a significant effect of faculty rank or role on resistance to change as a perceived barrier at the $\mathrm{p}<.05$ level $[\mathrm{F}(8,134)=2.17, \mathrm{p}=0.03]$ (see Table 7). Post hoc comparisons using the Tukey HSD test indicated that the mean score for the rank of assistant professor $(\mathrm{M}=3.81, \mathrm{SD}=1.55)$ was significantly different than the rank of clinical instructor $(\mathrm{M}$ $=5.63, \mathrm{SD}=5.18)$. However, there was no significant difference between any of the other rank or roles for the perceived barrier resistance to change.

There was a significant effect of faculty rank or role on lack of a timetable for implementing IPE as a perceived barrier at the $\mathrm{p}<.05$ level $[\mathrm{F}(8,133)=3.38, \mathrm{p}=.02]$ (see Table 7). Levene's indicated homogeneity was not met $[F=(8,133)=2.93, p=.00]$. However, second post hoc comparisons confirmed the Tukey HSD test which indicated that the mean score for the rank of assistant professor $(\mathrm{M}=3.31, \mathrm{SD}=1.51)$ was significantly lower than the rank of adjunct $(\mathrm{M}=4.43, \mathrm{SD}=0.95)$.

There was a significant effect of faculty rank or role on lack of time to develop new activities at the $\mathrm{p}<.05$ level $[\mathrm{F}(8,134)=3.34, \mathrm{p}=.02]$ (see Table 7). The post hoc Tukey HSD test indicated the mean score for clinical coordinators $(\mathrm{M}=4.88, \mathrm{SD}=.94)$ was significantly higher than assistant professors $(\mathrm{M}=3.77, \mathrm{SD}=1.42)$.

Years of Teaching Experience. There was a significant effect of years of teaching experience on lack of leadership as a barrier to IPE $\mathrm{p}<.05$ level $[\mathrm{F}(6,146)=2.14, \mathrm{p}=.05]($ see Table 8). Post hoc Tukey HSD indicated faculty with $11-15$ years of teaching experience $(\mathrm{M}=$ 
$3.05, \mathrm{SD}=1.39)$ rated lack of leadership as a barrier significantly lower than faculty with $21-25$ years $(\mathrm{M}=4.70, \mathrm{SD}=.94)$.

There was a significant effect of years of teaching experience on resistance to change as a barrier to IPE at the $\mathrm{p}<.05$ level $[\mathrm{F}(6,136)=2.16, \mathrm{p}=.05]$ (See Table 8). The Tukey HSD post hoc indicated faculty with only 0 - 5 years of teaching experience $(\mathrm{M}=4.93, \mathrm{SD}=1.38)$ rated resistance to change as a barrier to implementing IPE significantly higher than faculty with 31 years or more of teaching experience $(\mathrm{M}=3.54, \mathrm{SD}=1.56)$.

There was a significant effect of years of teaching experience on class sizes as a barrier to IPE at the $\mathrm{p}<.05$ level $[\mathrm{F}(6,136)=2.37, \mathrm{p}=.03]$ (see Table 8). The Tukey HSD post hoc indicated two areas of significant difference. Faculty with 0 - 5 years of teaching experience (M $=3.10, \mathrm{SD}=1.39)$ rated class sizes as a barrier to IPE significantly lower than faculty with 21 25 years of teaching experience $(M=4.70, S D=1.05)$; meanwhile, faculty with $21-25$ years of teaching experience $(M=4.70, S D=1.05)$ rated class size significantly higher than faculty with 31 years or more of teaching experience $(\mathrm{M}=2.69, \mathrm{SD} 1.25)$.

There was a significant effect of years of teaching experience on curriculum as a barrier to IPE at the $\mathrm{p}<.05$ level $[\mathrm{F}(6,135)=2.69, \mathrm{p}=.01]$ (see Table 8$)$. A Tukey HSD post hoc indicated that faculty with $21-25$ years of teaching experience $(\mathrm{M}=5.22, \mathrm{SD}=.83)$ rated existing curriculum significantly higher as a barrier than faculty with 31 or more years of teaching experience $(\mathrm{M}=2.92, \mathrm{SD}=1.44)$.

There was a significant effect of years of teaching experience on lack of time with existing IPE activities as a barrier to IPE at the $\mathrm{p}<.05$ level $[\mathrm{F}(6,135)=2.46, \mathrm{p}=.02)($ see Table 8). A Tukey HSD post hoc specified faculty with $16-20$ years of teaching experience (M $=4.56, \mathrm{SD}=1.22$ ) rated lack of time with existing IPE activities significantly higher than faculty 
with more than 31 years of teaching experience $(M=3.00, S D=1.22)$.

Location within the School of Allied Health. There was a significant effect of geographical location of athletic training programs within the institution and a lack of allied healthcare disciplines as a barrier to IPE. The Levene's test for homogeneity was not met, $[\mathrm{F}(2$, $136)=3.50, \mathrm{p}=.03]$ therefore, significance was identified with Welch's ANOVA $[\mathrm{F}(2,136)=$ 13.53, $\mathrm{p}=.03$ ] (see Table 9). Faculty who do not have their ATEP housed in the school of allied health rated lack of allied healthcare disciplines at their institution as a significantly greater barrier $(\mathrm{M}=3.70, \mathrm{SD}=1.82)$ than faculty whose ATEP is housed in the school of allied health $(\mathrm{M}=2.07, \mathrm{SD}=1.46)($ see Figure 7$)$.

Previous Experience with IPE. In the analysis of faculty's previous experience with IPE compared with perceived barriers for IPE, a significant difference was found between those with and without previous IPE experience and their perception of lack of knowledge as a barrier to $\operatorname{IPE}[\mathrm{F}(2,139)=.947, \mathrm{p}=.00]$ (see Table 10). With all assumptions met, faculty with no previous experience with IPE scored the barrier of lack of knowledge significantly higher $(\mathrm{M}=$ 4.32, $\mathrm{SD}=1.11)$ than faculty with previous IPE experience $(\mathrm{M}=3.43, \mathrm{SD}=1.31)$.

With all assumptions met, lack of time to develop IPE activities also has a significant difference between faculty with and without previous IPE experience (see Table 10). Faculty without previous IPE experience rated lack of time to develop IPE activities significantly higher $(\mathrm{M}=4.76, \mathrm{SD}=1.07)$ than faculty with IPE experience $(\mathrm{M}=4.20, \mathrm{SD}=1.36)$.

Perceived Skill Level with Using IPE. The analysis of faculty's perceived skill level with IPE compared with perceived barriers for IPE identified a significant difference with the barrier of lack of knowledge $[\mathrm{F}(4,137)=7.07, \mathrm{p}=.00]$ (see Table 11). With all assumptions met, the Tukey HSD distinguished significant difference between faculty who report having no 
skills for using IPE $(\mathrm{M}=4.46, \mathrm{SD}=.80)$ and those who have identified with having quite a bit of skills for using IPE $(M=3.06, \mathrm{SD}=1.43)$. Faculty with few IPE skills $(\mathrm{M}=4.44, \mathrm{SD}=1.07)$ rated the barrier of lack of knowledge significantly higher, than faculty who identified with having a moderate skill level for using IPE $(\mathrm{M}=3.75, \mathrm{SD}=1.27)$. While faculty who identified with having a moderate skill level for using IPE, rated lack of knowledge significantly higher than faculty who identified with having quite a bit of skills for using IPE (M=3.06, SD = 1.43).

\section{Summary}

The survey instrument, as inspired by the IEPS and The National Competency Framework (CIHC, 2010), provided quantitative data for the purpose of answering the five primary research questions. The research questions were inspired by the ultimate goal of identifying faculty's levels of perceived knowledge, readiness and perceived barriers for implementing IPE in an AT curriculum. An ANOVA was utilized for its robust ability to identify significant difference between groups when comparing groups of two or more. The post hoc analysis helped identify significant differences between faculty variables and the effect on faculty perception of knowledge, perceived level of readiness, perceived roles and responsibilities, perceptions of teamwork and collaboration, and perceived barriers to IPE. 


\section{Introduction}

\section{Chapter Five: Discussion}

As interprofessional communication continues to become an emerging topic in athletic training education, research verifies that it is a necessary part of healthcare education to ensure quality, well-rounded patient care (Kraemer \& Kahanov, 2014). However, there is still much debate about best practices surrounding the implementation of IPE into education programs. Before this study, literature did not possess data on faculty perceptions of IPE within athletic training education. The purpose of this study was to provide insight about athletic training faculty's knowledge and skills regarding IPE and to understand faculty's perceived barriers to implementing IPE in the didactic curriculum for athletic training education. The results of this study added to the body of literature by identifying faculty perceptions of IPE and the effect knowledge and preparation can have on faculty perceptions. Through a better understanding of faculty perceptions of IPE and the support of existing evidence, it is evident that there is an essential need for organized leadership, support and formal training for faculty specific to constructing and maintaining IPE programs.

\section{Summary of Results}

As expected, AT faculty report a diverse range of perceived knowledge and readiness for implementing IPE in their curriculum dependent on their demographic differences. More specifically, variables such as previous experience with IPE, perceived skill level, faculty rank, and the geographical location of a faculty member's ATEP within their institution had the greatest effect on knowledge perceptions and perceived readiness for implementing IPE (See Tables 2 - 5). Demographic variables such as faculty rank, years of teaching experience, extent of IPE skills, and geographical location of the ATEP also revealed a significant effect on athletic 
training faculty's perceived barriers for implementing IPE (See Tables 7-11). Each of these independent variables played a role in IPE perceptions, and that is further explained below.

Perceived Level of Readiness. In the exploration of faculty's perceived level of readiness to implement IPE in their AT education programs against their career experiences, it came as no surprise, that faculty who reported having previous experience with IPE $(\mathrm{M}=4.01$, $\mathrm{SD}=0.80$ ) rated their perceived level of readiness to implement IPE significantly higher than those without previous experience with IPE $(M=3.01, \mathrm{SD}=1.14)$. These results suggest that faculty with previous IPE experience feel they are ready to implement IPE, while those without previous experience only feel they are somewhat ready. Racine et al. (2016) compared previous experience and perceived skill level with perceived level of readiness among nursing faculty. The results revealed that faculty in nursing education who lacked knowledge and firsthand experience using IPE yielded lower levels of perceived readiness for implementing IPE in the classroom and clinical education. An extensive literature review was conducted on faculty readiness for IPE in athletic training education and no comprehensive evidence specific to perceived readiness of AT faculty could be found. Literature that encompassed AT faculty readiness for IPE only included small scale, preliminary studies, which all indicated future implications for large-scale research (MacDonald et al., n.d.; Breitbach \& Richardson, 2015; Klocko et al., 2012). It is ironic that any AT faculty report having substantial previous experience with using IPE strategies. IPE is a relatively novel teaching pedagogy (Breitbach \& Richardson, 2015); therefore, it is unlikely that many current faculty teaching in AT programs have ample amounts of previous experience with IPE activities specific to athletic training. It is possible, however, that those faculty with dual credentials, such as ATC and PT, may be more versed in IPE due to their interdisciplinary educational background. As IPE disperses throughout 
AT curriculum, it would be beneficial to further explore the relationship between perceived level of readiness and previous experiences with IPE.

The Effect of IPE Skill Level on Perceptions of IPE. The participants in this study represented varying degrees of skill levels for IPE implementation; ranging from having no skills in IPE to reportedly being proficient in IPE. Research by Abu-Rish et al. (2012), disclosed that most faculty in healthcare education cannot report how they obtained their IPE skills. In this study, participants were asked to reveal where they acquired their competence with IPE strategies. Many reported turning to the internet for IPE resources and pedagogies. There are many reliable published web-based modules available through reputable organizations such as the National Center for Interprofessional Practice and Education, the Institute of Medicine (IOM): 2013, World Health Organization (WHO, 2010) Framework for Action on IPE and Collaboration, and the IPEC 2016 Core Competencies. Many of these organizations also host national conferences specific to interprofessional collaboration. Faculty who prefer live interaction with the host can attend IPE lectures at national or state meetings to gain training on IPE for in the classroom. These are all valuable resources grounded by evidence-based research that support strategies for implementing interdisciplinary collaboration; however, there still remains the concern that evidence for IPE in health care education lacks the inclusion of athletic training education. Due to the unique nature of athletic training as a branch of health care delivery, it would be risky to assume transferability of IPE strategies across all health care disciplines (Geisler, 2015).

Besides the Racine et al. (2016) study of nursing faculty, previous studies on IPE have not addressed the effect of faculty member's skill levels with using IPE on their perceptions of knowledge and readiness to implement IPE. The results of this study found that perceived skill 
level of IPE has a significant effect on faculty perceptions of IPE. Faculty perceptions of skill level as it relates to their perceived roles and responsibilities for implementing IPE revealed a significant difference between all groups. Faculty who reported having no skills in IPE (M = $5.33, \mathrm{SD}=1.11)$ expressed greater uncertainty than faculty who identify with having few IPE skills $(\mathrm{M}=3.56, \mathrm{SD}=1.09)$, moderate IPE skills $(\mathrm{M}=2.48, \mathrm{SD}=1.06)$, and quite a bit of IPE skills $(\mathrm{M}=1.76, \mathrm{SD}=0.76)$. Overall, it appears as skill level increased, the faculty levels of uncertainty appeared to decrease (See Figure 5). It is important to note that the significant difference between faculty who rated their skills as proficient $(\mathrm{M}=2.40, \mathrm{SD}=2.19)$ only had a significant difference against those who expressed having no IPE skills $(\mathrm{M}=5.33, \mathrm{SD}=1.11)$. However, this interpretation should be taken with caution due to the nature of the mean and standard deviation for the proficient group being in such proximity to one another. Overall, these findings suggest that improving faculty skills for using IPE can enhance faculty's understanding of their roles and responsibilities. At this moment, AT faculty roles and responsibilities for implementing IPE still have not been cleared defined (Rizzo et al., 2015). Rather, it seems, as faculty gain IPE experience, they are gradually gaining an understanding of their roles for IPE. Faculty are being allowed to experiment with IPE techniques in the classroom before they fully know their role as an administrator of IP learning. This lack of certainty of faculty roles for IPE supports the idea that there exists a need for structured faculty training for IPE implementation (Abu-Rish et al., 2012; Breitbach \& Richardson, 2015, Loversidge \& Demb, 2015).

Faculty's perceived skill level with IPE also played a role in their perceived knowledge with IPE. The survey items that reflected perceived knowledge were derived from the data collected from the subcategory of competency and autonomy. These questions of competency 
and autonomy had a theme representing participants' perceptions of faculty within their same discipline of athletic training. Specifically, the results suggest that those who perceive themselves as having proficient skills for IPE $(M=3.37, S D=0.86)$, disagree that others in their profession have sufficient levels of competency. However, faculty who perceive themselves as having moderate $(\mathrm{M}=4.43, \mathrm{SD}=0.59)$, few $(\mathrm{M}=4.26, \mathrm{SD}=0.63)$ or no skills in IPE $(\mathrm{M}=$ $4.69, \mathrm{SD}=0.95)$ somewhat agree that others in their discipline have sufficient levels of competency and autonomy for IPE. Meaning that faculty who perceive themselves having less skills, think highly of the knowledge level of their peers and faculty who reported themselves as proficient with using IPE, did not feel that their peers possess as much knowledge. According to previous research, there is a lack of uniformity among ATs in their efforts for understanding professions outside of AT (Rizzo et al., 2015). Meanwhile, ATs feel other disciplines demonstrate a lack of competence in regards to the educational background, knowledge and skill base of the AT discipline and ATs have expressed a greater need for recognition as true healthcare professionals from other disciplines (Rizzo et al., 2015). This perceived lack of competence between health care disciplines affects interprofessional cooperation thus, creating a barrier to IP learning (Racine et al., 2016).

It is interesting to note that there was no significant difference among any of the other demographic categories regarding perceived knowledge of IPE. Of the athletic training faculty who participated in the study, perceived skill level appears to be the only factor creating distinguished views of the competency and autonomy of other faculty within their discipline. That being said, regardless of previous experience with practicing IPE, athletic training faculty from this study viewed lack of knowledge and lack of time to develop new IPE activities as barriers to implementing IPE. However, those without IPE experience perceived lack of 
knowledge $(\mathrm{M}=4.32, \mathrm{SD}=1.11)$ and time to develop activities $(\mathrm{M}=4.76, \mathrm{SD}=1.07)$ significantly more challenging than those with IPE experience $[(M=3.43, S D 1.31) ;(M=4.20$, $\mathrm{SD}=1.36)]$. It comes as no surprise that both barriers would be more challenging for those who do not have previous experience with IPE. It is evident that not having any previous introduction or practice with IPE would lead a faculty member to feel they have inadequate knowledge for implementing IPE. The issue of time for exploring ideas for new IPE activities could be particularly challenging for faculty without experience. Without previous experience in IPE, faculty need time to learn about IPE concepts and additional time to then construct activities for their curricula. With the inclusion of these findings, the results of this exploratory study continue to support the need for faculty training initiatives for IPE within AT educational curriculums.

Regardless of their acquired skills or previous experiences in IPE, the data expresses that AT faculty from this study believe AT faculty are knowledgeable about the aptitude of other allied healthcare professionals, but there is still room for improvement. There still remains the issue of understanding the perceptions of other healthcare professionals regarding ATs as members of the allied healthcare team. Existing literature suggests that ATs feel other healthcare professionals demonstrate a lack of competence in regards to the knowledge and abilities of ATs (Rizzo et al., 2015). ATs have expressed concern that other disciplines do not want to open their doors and share learning because they fear losing their position in the workplace. Previous research on IPE exposed the possibility of a perceived existence of a "turf war" among health care disciplines prohibiting access to learning interdisciplinarily (Racine et al., 2016). IPE is not intended to over-rule and eliminate healthcare specialties; its purpose is to teach students to work 
as members of a healthcare team that incorporates multi-disciplinary approaches to serving their patients (Rizzo et al., 2015).

Perceptions of Interdisciplinary Cooperation. It is evident the topic of interdisciplinary competency and autonomy does not develop without conversations about cooperation. The results of this study showed a significant difference between geographical location of the ATEP within its institution on actual cooperation among faculty of assorted disciplines. The results suggest that faculty whose ATEP is housed within the school of allied health, agree that individuals in the athletic training education profession work well with each other, think highly of other related professions, are able to work closely with individuals in other professions, are willing to share information and resources with other professionals and have good relations with people in other professions $(\mathrm{M}=4.37, \mathrm{SD}=0.64)$. Due to the recent mandate by CAATE (2016) that requires ATEPs to align with schools of allied health within their institution, this barrier may diminish in importance over time. The number of years housed in the allied health school was not investigated in this study; future research on the effects of IPE may benefit from this type of data.

ATs in the field were taught they operate under the direction of a supervising physician; however, the day-to-day role of an AT does not always depend on direct support from a physician. The faculty in this study expressed respect for the autonomy that ATs have in the workplace, but also express a need for cooperation among disciplines for IP learning. Faculty who do not have their ATEP housed in the school of allied health also expressed a lack of access to allied healthcare disciplines at their institution as a significantly greater barrier $(\mathrm{M}=3.70, \mathrm{SD}$ $=1.82)$ compared to faculty who do have their ATEP housed in the school of allied health $(\mathrm{M}=$ $2.07, \mathrm{SD}=1.46)$. According to the findings of this study, the location of the ATEP seems to 
play a major role in the perceived access and levels of cooperation for interdisciplinary learning.

In recent research, many institutions have reported that collaborating with faculty from multiple disciplines has been proven useful for designing IPE programs (Rafter, Pesun, Herren, Linfante, Mina, Wu \& Casada, 2006). However, as supported by the results of this study, physical proximity poses a major issue for AT programs scheduling common courses interdisciplinary (Rafter et al., 2006). Just based on the small population of this study, there still remains quite a few ATEPs that are not operating within their school of allied health sciences. It is apparent that bringing faculty from different disciplines together can be inhibited by the physical roadblock of geographical location. Other studies of faculty perceptions of IPE in healthcare education indicate it takes a great deal of cooperation to schedule classes in conjunction with other disciplines within the same college. It is not uncommon for different disciplines to operate under different term systems and be governed by various accreditation bodies; this has posed barriers on faculty (Rafter et al., 2006). When programs are housed within the same school on campus, they tend to fall under the same administrative umbrella, which has reportedly helped alleviate the barrier of scheduling IPE. In a survey administered to program directors of professional AT programs regarding their program's involvement with IPE, the outcomes revealed $69 \%$ of the total programs who reported "yes" to having involvement in IPE initiatives, also had their programs housed in an academic unit with other health professions (Breitbach \& Cuppett, 2012). This detail supports the theory that AT programs housed in schools or colleges with other healthcare professional programs may have more convenient access to opportunities for IPE. 
Having an athletic training program housed within the school of allied health apparently fosters ease of access to other allied health care disciplines within one's institution. CAATE has also recognized this fact, hence the newly imposed requirement that all ATEPs must be located within the school or college of allied health or the like (CAATE, 2016). Programs who cannot provide residency among other allied health disciplines will have to justify to how they are providing their students the same benefits as those programs which reside among other allied health care disciplines within their institution. Athletic training is developing into a profession of primary caregivers for their patient population. This evolution comes with newly proposed competencies that include skills such as, suturing, EKG screening, urinalysis, and phlebotomy (CAATE, 2016). Many current athletic training programs have expressed concerns with their faculty's ability to teach these new competencies to students, and CAATE's solution is interprofessional education. The integration of interdisciplinary activities with the inclusion of the athletic training profession, will not only benefit AT educational programs, it will help all healthcare disciplines meet accreditation standards for incorporating IPE (Zorek \& Raehl, 2013).

Perceived Barriers for IPE. Embedding IPE strategies into existing curricula requires critical resources. Faculty in health care have expressed major constraints such as scheduling restrictions, insufficient personnel, lack of technological resources, already crowded curricula, inadequate physical space, difficulty bringing students from varied disciplines together, and insufficient time for curricular planning (Lapkin et al., 2013; Bridges et al., 2011; Becker \& Godwin, 2005). Institutions who have initiated collaboration with multiple disciplines within their school have also reported issues with the collaboration of academic calendars, curricular mapping, and managing large student cohorts (Lapkin et al., 2013). The AT faculty who participated in this study expressed similar barriers as other health care faculty; however, they 
also seem to face issues of adversity such as political tension, lack of leadership and resistance to change.

It was hypothesized that there would be differences in perceived barriers among AT faculty depending on their rank or role within their program and the results supported this hypothesis. Clinical instructors and professors in ATEPs had significantly different viewpoints on impedances of IPE. The results suggest that a rank of professor, compared to a rank of clinical instructor, has an effect on faculty perceptions of lack of leadership as a perceived barrier. Specifically, our results suggest that professors moderately disagree $(\mathrm{M}=2.65, \mathrm{SD}=$ 1.43) that a lack of leadership creates a barrier for them to implement IPE in their teaching pedagogies, while clinical instructors somewhat agree $(\mathrm{M}=4.50, \mathrm{SD}=1.41)$ that a lack of leadership forms a barrier to the implementation of IPE in their teaching pedagogies. Even though a significant difference only existed between these two faculty rankings, it is important to note that other lower ranked faculty, such as assistant instructors and adjuncts also rated leadership as a substantial barrier to implementing IPE (See Figure 6).

Not only do the clinical instructors from this study express challenges with a lack of leadership, but they also convey concerns of political tension and resistance to change within their institutions. The results suggest that the rank of clinical instructor compared to higher ranked faculty has an effect on the perception of political tension as a perceived barrier to IPE. Specifically, clinical instructors strongly agree that political tension $(\mathrm{M}=5.25, \mathrm{SD}=0.70)$ and resistance to change $(M=5.63, S D=5.18)$ create a barrier for them to implement IPE in their teaching pedagogies. Overall, higher ranked faculty from this study did not disagree with political tension as a potential barrier to IPE; however, their level of agreeance was significantly lower than the clinical instructors. As for resistance to change, the results suggest that assistant 
professors somewhat disagree $(\mathrm{M}=3.81, \mathrm{SD}=1.55)$ that resistance to change creates a barrier for them to implement IPE in their teaching pedagogies, while clinical instructors strongly agree that resistance to change presents a barrier to the implementation. Overall, these results suggest that junior faculty perceive resistance to change within their institutions. Previous IPE research discloses resistance to change from senior faculty members as a consistent barrier that appears across disciplines (Loversidge \& Demb, 2015). Grassroots efforts for IPE implementation have been proven effective at eliminating inclusion barriers among faculty. It is possible for leadership frameworks for IPE implementation to have a scaffold that originates from the bottom, with junior faculty mentoring senior faculty. Inclusion of junior faculty in curricular and programmatic planning has been recommended to neutralize the barriers of resistance and political tension among faculty (Loversidge \& Demb, 2015).

With that in mind, it is important to acknowledge the unique structure of faculty rank and roles, its relation to teaching experience and the effect they have on perceived barriers to IPE. Years of teaching experience often coincides with faculty rank; however, this should not always be assumed. Some faculty may contribute to education as an adjunct for their entire careers, or clinical instructors may never aspire to advance to professorship. With rank and role put aside, the data analysis in this study explored possible differences between years of teaching experience and its effect on perceived barriers to IPE. The results of the comparison of years of teaching experience reveal different concerns with leadership and resistance to change in relation to faculty rank. The results of this study suggest that faculty with upwards of 20 years of experience perceive a lack of leadership as a greater barrier than the faculty with less teaching experience. Additionally, faculty with only 0-5 years of teaching experience $(\mathrm{M}=4.93, \mathrm{SD}=$ 1.38) expressed resistance to change as a substantial barrier to their implementation of IPE 
compared to faculty with 31 years or more of teaching experience $(\mathrm{M}=3.54, \mathrm{SD}=1.56)$. These results suggest that faculty in their early years of teaching, feel there is a resistance to change within their programs and their institutions. The interpretation of these results can go several directions. One might presume that faculty with more teaching experience would be assuming more of a leadership role within their programs. Although IPE is a rather novel concept for athletic training, it is not novel to health care education. It is possible that newer faculty are emerging as recent graduates of post-professional programs where interprofessional practices are frequently a part of conversations. As newer faculty emerge into AT programs, it is possible they would be willing to take a lead role in the implementation by sharing their knowledge and experiences with IPE, but feel as if their colleagues are resisting making changes to their pedagogies. Once again, this supports the idea that it should be considered a possibility that leadership for initiating IPE may need to come from the bottom up.

According to the sample of faculty from this study, it would appear that faculty who possess a lower ranking such as clinical instructors and adjuncts articulated concerns with a lack of leadership, an existence of political tension and resistance to change within their programs and institutions. Existing literature expresses lack of leadership as a barrier to IPE, but political tension and resistance to change are unique to this study specific to AT faculty. Other disciplines who have successfully integrated IPE in their healthcare education programs attribute their success to administrative support. This support included active collaboration with deans, curriculum committees, and educational administrators. This administrative support was imperative during the initiation stages of IPE development, while the vitality of IPE as a component of programmatic infrastructure was highly dependent on leadership from program directors and veteran faculty (Bridges et al., 2011). There appears to be an inherent need for 
proper leadership within institutions for successful development of IPE programs. Committed and experienced faculty is necessary to provide adequate IPE leadership. In some cases, it was highly recommended to designate an individual to have the role with the responsibility of IPE coordinator (Rafter et al, 2006; Thistlethwaite \& Nisbet, 2011). This individual is needed to take charge of the promotion and coordination of all IPE activities, be the interdisciplinary faculty liaison and ensure that faculty IP mentorships are readily available (Thistlethwaite \& Nisbet, 2011). The designation of a single faculty member for the role of IPE liaison, may also prove to provide more financial feasibility for programs. It could be costly to send multiple faculty to conferences to learn about IPE, but it may be cost effective to appoint one member of the faculty to attend IPE conferences and be responsible for sharing their knowledge acquired with the rest of the faculty.

Altogether, the responses to this study suggest that faculty in athletic training are facing critical barriers that are hindering the integration of IPE. The research of Bridges et al. (2001) encourages the creation of IPE leadership frameworks and expresses that the barriers of IPE can be overcome with persistence and commitment from faculty and administration. According to the sample of faculty in this study, there is an apparent need for appropriate faculty mentoring, commitment and leadership from faculty and staff of all departments and colleges involved to implement successful IPE in athletic training curricula (Bridges et al., 2011).

\section{Implications for Athletic Training Education}

Addressing these barriers facing athletic training faculty is imperative considering the current status of athletic training education. As the athletic training profession transitions to the professional master's level, one of the goals will be to get interprofessional educational strategies mainstreamed into the curricula and clinical practices of all health care professions. CAATE 
standards have included a statement to include IPE for many years (former standard 44), but now CAATE's most recent operational standards stress the requirement for planned interprofessional education across the professional program through Standard 14. CAATE elaborates on this standard with the explanation that methods for IPE can vary across programs, but "they must occur on a planned and continuous basis across the curriculum. A single exposure to interprofessional education does not meet this standard." (CAATE, 2016, p.4)

This guideline from CAATE provides programs with the understanding that they must integrate IPE, yet a precise definition of what constitutes as IPE integration is still left for interpretation by program faculty and directors. CAATE recognizes the fact that many health care education programs tend to operate in separate academic units within an institution and can be housed distances away from one another. CAATE also acknowledges that it is not uncommon for professional programs to operate under separate administrative governance with independent programmatic agendas. These agendas are often aimed towards the preservation of the special interests of their particular discipline. CAATE believes athletic training students "should be provided with as many opportunities as possible for intentional interprofessional collaboration with educators, practicing clinicians, and students from other health professions." (CAATE Post-Professional Degree Standards, 2014, p.3). To overcome the biases that come with siloed, uniprofessional learning and to help with the socialization of athletic training into healthcare education, CAATE has implemented the standard regarding administrative alignment of professional master's programs. This standard is intended to be applied no later than the 2019 - 2020 academic year and will require professional master's programs to be housed among similar health care education programs at their institution. Meeting this requirement may come with the effort of physically restructuring departments and altering programmatic hierarchy to 
provide appropriate leadership and access to more opportunities for interdisciplinary collaboration among faculty and students.

In a review of IPE across healthcare disciplines, it was articulated that "clearer specifications of minimal reporting requirements are useful for developing and testing IPE models that can inform and facilitate successful translation of IPE best practices into academic and clinical practice arenas." (Abu-Rish, et al., 2012, p.444). The CAATE standards fail to provide official provisions for how athletic training education programs should promote interdisciplinary collaboration in the classroom, in the clinical setting, and in the workplace. There are existing resources, such as those initiated by the World Health Organization (Gilbert, Yan, \& Hoffman, 2010), that delineates frameworks for integrating health care policy and IPE. Frameworks supported by organizations such as the WHO provide a valuable list of suggestions on how collaborative practices can be executed. It is important that AT programs find a way to educate AT students on the value of working with other health care professionals as one interdisciplinary team to provide complete, well-rounded patient care. There are fundamental advantages to having a strong team of medical professionals that work together to provide the best possible care for a patient (Gilbert, Yan, \& Hoffman, 2010). In the workplace, athletic trainers assume the responsibility to promote and protect the overall health and well-being of their athletes, but this task is best not taken on alone. Although research for successful IPE implementation in health care education exists, it would be most beneficial for athletic training faculty to have more specifically delineated guidelines from CAATE itself to help initiate the necessary leadership and guidance needed for programs to begin to integrate this new standard. Implications for the Health Sciences 
The inclusion of the athletic training profession into interprofessional practice has significant implications for health sciences; with specific positive outcomes for the delivery of better patient care. Athletic trainers possess a unique educational background and multiple skill sets that can enhance the integrity of existing health care teams. Active communication among all members of the healthcare team has the potential to improve patient care and clinical outcomes; therefore, research suggests the incorporation of a comprehensive team of interdisciplinary professionals to ensure best patient care is delivered (World Health Organization [WHO], 2010). Injury and illness prevention and management strategies for complex conditions such as sport-related concussions, are starting to adopt guidelines that include team-based approaches to health care delivery (Pabian, Oliveira, Tucker, Beato \& Gual, 2017). It is recommended that health care personnel incorporate an athletic trainer on their health care team to ensure optimal, informed decision making for patient care. These team-based approaches are aimed towards creating comprehensive injury management plans. The athletic trainer is often the first line of defense for the recognition, prevention, and treatment of injury and illness for their patients, due to their continuous access to their patients. These interdisciplinary approaches can help assimilate other healthcare professionals into the wellness management for the physically active population. One possible way to begin the integration of interdisciplinary practices, may be for allied health faculty to collaborate in current research on IPE together.

\section{Future Implications}

The ultimate question remains of how programs can feasibly incorporate elaborate IPE practices into their curriculum. Athletic training faculty are aware of the inherent need for collaborative learning yet, there remains the concern of time and coursework that is already 
overloaded with competencies to cover. The other factor that remains unanswered for athletic training faculty is in reference to how encompassing the new standard for IPE integration will actually be. Athletic training faculty should consider whether IPE needs to exist somehow in every course, and how much programmatic restructuring will need to be done to incorporate effective IPE. Evidence from other allied health fields discloses it is possible that individual courses and program matrixes would need a complete overhaul to effectively implement IPE. It is a reality that IPE needs to be strategically planned. It is advised that administrators and educators come to a general consensus that IPE will be made a priority. Evidence advocates consistent integration of IPE throughout program curricula and suggests that current policies that inhibit IPE innovations should be reconsidered. An additional critical implication is the engagement of adjuncts and clinical faculty members. These faculty members often serve essential roles in education and are necessary for closing the outcome loops in IPE for clinical practice (Loversidge \& Demb, 2015).

Evidence in existing literature highly suggests formal training for faculty that addresses their roles, responsibilities, and strategies for implementing IPE. A systematic overview of interdisciplinary practices within health science education attributes faculty development as an essential component of facilitating IPE competencies (Abu-Rish et al., 2012, Reeves et al., 2013; Silver \& Leslie, 2009; Steinert, 2005). Without proper training, faculty felt unprepared as a developer and facilitator of activities, especially when multiple health professions were involved. Abu-Rish et al. (2012) identified a deficiency with programs reporting formal faculty training for IPE. Those programs who did report conducting official faculty development programs expressed that it requires significant administrative support and in some cases, grant funding was necessary to drive collaborations between individual health professional schools. 
To overcome these challenges, there may be a need for a designated administrator or faculty member to have IPE development as part of their faculty load.

Geographical location, time, and scheduling difficulties continue to be logistical barriers affecting readiness to implement IPE. Presently, the traditional institution of higher education may consist of multiple geographical sites and not all allied health disciplines may reside on the same physical campus, impeding connections with faculty from other allied health disciplines. One suggestion for overcoming the barriers with planning physical interaction for IPE is the integration of technology. Researchers are exploring the possibilities using technological resources such as online social networks that serve the purpose of promoting interprofessional collaboration (Gray \& Smyth, 2012; Yang, 2009; Becker \& Godwin, 2005). Asynchronous discussion boards that provide an interactive medium where learners can exchange knowledge and ideas has been recognized as one of the most successful applications of community collaboration. Compared to a traditional classroom setting, all students had the opportunity to contribute to the discussion.

Utilizing web-based technology can provide an attainable, active environment where collaborative knowledge construction and group knowledge sharing can be practiced and promoted (Yang, 2009). It is becoming more common to see online classes offered in higher education and, even more so, hybrid courses that provide less time lecturing in the classroom and ideally more time for discussion, collaboration and practical activities in the classroom. Many health care education programs are transitioning to more hybrid style courses in attempts to transform their programs into student-centered learning programs where the educator can convert into a role of facilitator rather than a deliverer of knowledge (Wright, et al., 2002). Assimilating the use of computer technology provides the power of scheduling flexibility for both students 
and faculty. Since barriers of time and scheduling of physical interactions continue to be a barrier across healthcare disciplines, future endeavors for IPE implementation should consider the use of technology.

Ultimately, the effectiveness of these strategies to implementing interprofessional practices through different mediums will need to be evaluated. Universally, there exists a lack of evidence for competency-based assessments for IPE programs. Since IPE is a novel construct in athletic training, assessing IPE programs will be critical in the years to come. If faculty concerns regarding IPE implementation are going to be overcome, then appropriate leadership, instruction, evaluation, and support needs to be provided. This leadership starts with accrediting bodies, accompanied by the transfer of responsibility to dean, program directors and their associated personnel.

Now, more than ever, athletic training students need to learn how to be active members of the healthcare team. Evidence from this study suggests a lack of understanding of how other disciplines perceive athletic training as an allied healthcare profession. Faculty who participated in this study expressed an overall need for more cooperation. Gaining a clearer understanding how other healthcare disciplines perceive the professional culture, disciplinary status, and role of athletic trainers as members of the healthcare team could help clarify the all-inclusive needs to facilitate collaboration. Athletic training faculty may need to be the ones who spearhead IPE on their campuses. Interprofessional education does not have to incorporate entirely novel ideas, rather athletic training faculty can continue to participate in the activities they are already doing in their programs, but invite other disciplines to participate, and it will have the potential to grow into a campus-wide interprofessional initiative. At this point, evidence demonstrating effective IPE initiatives specifically for AT education is scarce; faculty in AT must turn to IPE models in 
other disciplines for guidance. This may prove to be effective to start the IPE initiate; however, there will most likely be a need for more research to help meet the specific needs of athletic training education.

\section{Strengths and Limitations}

This study investigated perceptions of IPE of current faculty in athletic training. The focus of literature in support of this study was limited to predominantly findings from IPE in other healthcare disciplines since evidence was limited for IPE specifically for athletic training education. Although the survey sampling attempted to cover a broad range of faculty in athletic training across the United States, the survey distribution was limited to faculty who were also active members of the NATA who identified themselves with the professional setting of education. Identification of professional setting with the NATA is not a requirement, so it is possible that access to a robust nationwide faculty sample was limited because it was reliant on faculty choosing to update their professional setting with their NATA membership.

The survey response rate also posed a limitation. With a response rate of less than $30 \%$ of the overall sample population, generalizing to the overall population of athletic training faculty should be done with caution. The interpretation of the results may also be taken with caution due to the assumption that the participants already possess their own form of understanding to definitions and concepts of IPE. The term interprofessional education was not defined for the participants with the intention of gaining insight to the subject's current knowledge of IPE. It is possible the participant's knowledge level of IPE could have influenced their interpretation of the questions and coincidentally their survey responses.

Despite the small sample size, this study demonstrates strengths of a stratified random sample. The groups represented in the sample population comparatively covered the diverse 
demographics of athletic training faculty, and served its purpose for the data analysis. The results of this study can also be considered a strength of this study because the identified barriers affecting knowledge, readiness and perceptions of IPE among athletic training faculty align with existing literature of IPE for other disciplines in healthcare education.

Further research including perceptions of preceptors could help to provide insight on the needs for extending IPE into clinical education. As IPE emerges into athletic training education, outcomes should be continually measured to determine the effectiveness of IP experiences. There are reliable instruments such as the modified Readiness for Interprofessional Learning Scale (mRIPLS) available to determine faculty, student and clinician attitudes towards IPE experiences (Welsch, Rutledge, \& Hoch, 2017). Research of this nature can help provide feedback to create better guidelines and training for faculty directing IPE. The benefits of IPE for athletic training students and faculty should be further explored, including the ramifications of IPP on patient outcomes with the inclusion of the athletic training professional.

\section{Conclusions}

Faculty throughout healthcare education are progressively experimenting with new IPE tactics; however, they still articulate concerns with readiness for IPE interventions. If IPE strategies are expected to be a component of athletic training education, it is critical to understand the challenges faculty face so this knowledge can be utilized to construct faculty support systems and development programs for the implementation of IPE in their academic curriculum (Abu-Rish, et al., 2012). Based on existing outcomes for research in IPE, we know that combining resources across disciplines can broaden the opportunity for student success. Students grounded through IPE approaches are more likely to develop into collaborative interprofessional team members who exhibit positive attitudes and mutual respect towards their 
colleagues, which ultimately results in improved patient outcomes (Bridges et al., 2011). One discipline may contribute a resource that another may lack and together they form a comprehensive set of resources. The researcher's hypotheses regarding perceptions and barriers for IPE were supported by the results of this study. As planning for IPE implementation is initiated, it could be valuable to keep in mind that AT faculty's level of readiness, including their knowledge and understanding of their roles and responsibilities for IPE, are dependent on factors such as rank, role, years of teaching experience, and previous experience with IPE. IPE integration should include initiatives that provide administrative support, delineated leadership roles and efforts for bringing allied health disciplines in closer physical proximity on their campuses. As the profession of athletic training elevates to a new level of health care delivery with the new CAATE competencies and the transition to the professional master's educational requirement, evidence strongly supports the integration of interprofessional teaching and learning. The challenge of bringing different disciplines together remains; meanwhile, its' apparent need is evident now more than ever. 


\section{References}

Abu-Rish, E., Kim, S., Choe, L., Varpio, L., Malik, E., White, A., \& Thigpen, A. (2012). Current trends in interprofessional education of health sciences students: A literature review. Journal of Interprofessional Care, 26(6), 444-451.

Becker, E. \& Godwin, E. (2005) Methods to Improve Teaching Interdisciplinary Teamwork through Computer Conferencing. Journal of Allied Health, 34(3), 169-176.

Bishop, P. A., \& Herron, R. L. (2015). Use and Misuse of the Likert Item Responses and Other Ordinal Measures. International Journal of Exercise Science, 8(3), 297-302.

Breitbach, A. \& Cuppett, M. (2012) Inclusion of athletic training faculty and students can enhance interprofessional education programs. Paper presented at: Association of Schools of Allied Health Professions Annual Meeting; Orlando, FL.

Breitbach, A., \& Richardson, R. (2015). Interprofessional Education and Practice in Athletic Training. Athletic Training Education Journal, 10(2), 170-182.

Bridges, D. R., Davidson, R. A., Odegard, P. S., Maki, I. V., \& Tomkowiak, J. (2011). Interprofessional collaboration: Three best practice models of interprofessional education. Medical Education Online, 16(6035), 1-10. DOI: 10.3402/meo.v16i0.6035

Canadian Interprofessional Health Collaborative (CIHC). (2010). A national interprofessional competency framework. Retrieved from http://www.cihc.ca/files/CIHC_IPCompetencies_Feb1210.pdf

Carifio, J., \& Perla, R. J. (2007). Ten common misunderstandings, misconceptions, persistent myths and urban legends about Likert scales and Likert response formats and their antidotes. Journal of Social Sciences, 3(3), 106-116.

Caswell, S., \& Gould, T. (2008). Individual moral philosophies and ethical decision making of 
undergraduate athletic training students and educators. Journal of Athletic Training, 43(2), 205-214.

Commission on Accreditation of Athletic Training Education (CAATE). (2013) Standards for the Accreditation of Post-Professional Athletic Training Degree Programs. Retrieved from http://caate.net/wp-content/uploads/2014/05/2014-Standards-for-Accreditation-of$\underline{\text { Post-Professional-Degree-Programs21.pdf }}$

Commission on Accreditation of Athletic Training Education. (2016). Standards for the Accreditation of Professional Athletic Training Program. Retrieved from http://caate.net/wp-content/uploads/2016/04/2016-CAATE-Standards-Accd-ProfessionalAthletic-Training-Programs_VF.pdf

Commission on Accreditation of Athletic Training Education (CAATE). (2016) Update on operational standards and curricular content standards drafts. Insight - A Publication from the Commission on Accreditation of Athletic Training Education. 1-9

Commission on Accreditation of Athletic Training Education (CAATE). (n.d.). Retrieved from https://caate.net/about/

Ekmekci, O. (2013). Promoting Collaboration in Health Care Teams through Interprofessional Education: A Simulation Case Study. International Journal Of Higher Education, 2(1), $78-83$.

Fan, S., Radford, J., \& Fabian, D. (2016). A mixed-method research to investigate the adoption of mobile devices and Web2.0 technologies among medical students and educators. BMC Medical Informatics and Decision Making, 16(43), 1-8.

Gilbert, J., Yan, J., \& Hoffman,S. (2010). A WHO report: framework for action on interprofessional education and collaborative practice. Journal of Allied Health, 39(1), 
196-197.

Gray, C., \& Smyth, K. (2012). Collaboration Creation: Lessons Learned from Establishing an Online Professional Learning Community. Electronic Journal Of E-Learning, 10(1), 6075.

Hagemeier, N. E., Hess, R., Hagen, K. S., \& Sorah, E. L. (2014). The impact of an interprofessional communication course in nursing, medical, and pharmacy students' communication skill self-efficacy beliefs. American Journal of Pharmacy Education, 78(10), 186-195. http://dx.doi.org/10.5688/ajpe7810186

Joint Statement from the Strategic Alliance BOC, CAATE, NATA, and NATA Foundation. (2015). Retrieved from www.Strategic-Alliance-CCATE-pdf.pdf

Keller, K. B., Eggenberger, T. L., Belkowitz, J., Sarsekeyeva, M., \& Zito, A. R. (2013). Implementing successful interprofessional communication opportunities in health care education: a qualitative analysis. International Journal of Medical Education, 4, 253-259.

Klocko, D.J., Hoggatt Krumwiede, K., Olivares-Urueta, M., \& Williamson, J.W. (2012). Development, implementation, and short-term effectiveness of an interprofessional education course in a school of health professions. Journal of Allied Health, 41(1), 14-20.

Kraemer, E., \& Kahanov, L. (2014). Development of Interprofessional Education for Entry Level Athletic Training Programs. International Journal of Athletic Therapy and Training, 19(6), 4-7.

Lapkin, S., Levett-Jones, T., \& Gilligan, C. (2013). A systematic review of the effectiveness of IPE in health professional programs. Nurse Education Today, 33(2), 90-102.

Lie, D., Fung, C., Trial, J., \& Lohenry, K. (2013). A comparison of two scales for assessing health professional students' attitude toward interprofessional learning. Medical Education 
Online, 18(21885), 1-10.

Loversidge, J., \& Demb, A. (2015). Faculty perceptions of key factors in interprofessional education. Journal of Interprofessional Care, 29(4), 298-304.

Luecht, R. M., Madsen, M. K., Taugher, M. P., \& Petterson, B. J. (1990). Assessing professional perceptions: Design and validation of an interdisciplinary education perception scale. Journal of Allied Health, 19(2), 181 - 191.

MacNaughton, K., Chreim, S., \& Bourgeault, I. L. (2013). Role construction and boundaries in interprofessional primary health care teams: a qualitative study. BioMed Central Health Services Research, 13, 486-499.

McFadyen, A. K., Maclaren, W. M., \& Webster, V. S. (2007). The interdisciplinary education perception scale (IEPS): An alternative remodeled sub-scale structure and its reliability. Journal of Interprofessional Care, 21(4), 433-443.

National Athletic Trainer's Association. (2017). About. retrieved from http://www.nata.org/about

Pabian, P.S., Oliveira, L, Tucker, J., Beato, M., \& Gual, C. (2017). Interprofessional management of concussion in sport. Physical Therapy in Sport, 23, 123-132.

Pinilla, S., Weckbach, L., Alig, S., Bauer, H., Noerenberg, D., Singer, K., \& Tiedt, S. (2013). Blogging Medical Students: A Qualitative Analysis. GMS Zeitschrift Für Medizinische Ausbildung, 30(1), Doc9. http://doi.org/10.3205/zma000852

Racine, L., Bilinski, H., \& Spriggs. (2016). Nursing Faculty's Needs of Knowledge, Beliefs, and Readiness to Implement Interprofessional Education in their Teaching: An Exploratory Study. Quality Advancement in Nursing Education - Avancées en formation infirmière, 2(1), 1-19. 
Rafter, M., Pesun, I., Herren, M., Linfante, J., Mina, M., Wu, C., \& Casada, J. (2006). A Preliminary Survey of Interprofessional Education. Journal of Dental Education, 70(4), 417-427.

Ravet, J. (2012). From interprofessional education to interprofessional practice: Exploring the implementation gap. Professional Development in Education, 38(1), 49-64. http://dx.doi.org/10.1080/19415257.2011.576263

Reeves, S., Perrier, L., Goldman, J., Freeth, D., \& Zwarenstein, M. (2013) Interprofessional education: effects on professional practice and healthcare outcomes (update). Cochrane Database of Systematic Reviews. (3). DOI: 10.1002/14651858.CD002213.pub3

Rizzo, C. S., Breitbach. A. \& Richardson, R. (2015). Athletic trainers have a place in interprofessional education and practice. Journal of Interprofessional Care, 29(3), 256257.

Sanborn, H. (2016). Developing asynchronous online interprofessional education. Journal of Interprofessional Care, 30(5), 668-670.

Silver, I. L., \& Leslie, K. (2009). Faculty development for continuing interprofessional education and collaborative practice. Journal of Continuing Education in the Health Professions, 29(3), 172-177.

Steinert, Y., Cruess, S., Cruess, R., \& Snell, L. (2005). Faculty development for teaching and evaluating professionalism: from programme design to curriculum change. Medical education, 39(2), 127-136.

Tashiro, J., Byrne, C., Kitchen, L., Vogel, E., \& Bianco, C. (2011). The development of competencies in interprofessional health care for use in health science educational programs. Journal of Research in Interprofessional Practice and Education, 2(1), 63-82. 
Thistlethwaite, J.E. \& Nisbet, G. (2011) Preparing educators for interprofessional learning: rationale, educational theory and delivery. A sociological perspective on interprofessional education., Nova, New York, pp. 169-184.

Tivener, K. A., \& Gloe, D. S. (2015). Designing Simulations for Athletic Training Students Through Interprofessional Teaching Collaboration. Athletic Training Education Journal, 10(3), 249-255.

Welsch, L.A., Rutledge, C., Hoch, J.M. (2017) The modified readiness for interprofessional learning scale in currently practicing athletic trainers. Athletic Training Education Journal, 12(1), 10-17

Wright, K. E., Stewart, J., Wright, V. H., \& Barker, S. (2002). eLearning: Is There a Place in Athletic Training Education? Journal of Athletic Training, 37(4 suppl), S-208-S-212. Yang, S.H. (2009). Using Blogs to Enhance Critical Reflection and Community of Practice. Educational Technology \& Society, 12 (2), 11-21.

Yarborough, M., Jones, T., Cyr, T. A., Phillips, S., \& Stelzner, D. (2000). Interprofessional education in ethics at an academic health sciences center. Academic Medicine, 75(8), 793-800.

Zorek, J. \& Raehl, C. (2013) Interprofessional education accreditation standards in the USA: a comparative analysis. Journal of Interprofessional Care. 27(2), 123-130.

Zwarenstein, M, Goldman, J, \& Reeves, S. (2009) Interprofessional collaboration: effects of practice-based interventions on professional practice and healthcare outcomes. Cochrane Database of Systematic Reviews. 3. DOI: 10.1002/14651858.CD000072.pub2 
Table 1

Demographics of Sample (Frequency Distribution)

\begin{tabular}{|c|c|c|c|c|}
\hline \multicolumn{2}{|c|}{ Faculty Rank or Role } & \multicolumn{2}{|c|}{ Frequency } & Percent \\
\hline \multirow[t]{10}{*}{ Valid } & Program Director & \multicolumn{2}{|c|}{23} & 12.2 \\
\hline & Clinical Coordinator & \multicolumn{2}{|c|}{31} & 16.4 \\
\hline & Professor & \multicolumn{2}{|c|}{27} & 14.3 \\
\hline & Associate Professor & \multicolumn{2}{|c|}{8} & 4.2 \\
\hline & Assistant Professor & \multicolumn{2}{|c|}{36} & 19.0 \\
\hline & Adjunct & \multicolumn{2}{|c|}{34} & 18.0 \\
\hline & Visiting Instructor & \multicolumn{2}{|c|}{13} & 6.9 \\
\hline & Clinical Instructor & \multicolumn{2}{|c|}{9} & 4.8 \\
\hline & Assistant Instructor & \multicolumn{2}{|c|}{5} & 2.6 \\
\hline & Total & \multicolumn{2}{|c|}{186} & 98.4 \\
\hline \multicolumn{2}{|c|}{ Missing System } & \multicolumn{2}{|c|}{3} & 1.6 \\
\hline \multicolumn{2}{|c|}{ Total } & \multicolumn{2}{|c|}{189} & 100.0 \\
\hline \multicolumn{2}{|c|}{ Years of Teaching Experience } & \multicolumn{2}{|c|}{ Frequency } & Percent \\
\hline \multirow[t]{8}{*}{ Valid } & -5 Years & \multicolumn{2}{|c|}{40} & 21.2 \\
\hline & $5-10$ Years & \multicolumn{2}{|l|}{42} & 22.2 \\
\hline & $11-15$ Years & \multicolumn{2}{|l|}{25} & 13.2 \\
\hline & 16-20 Years & \multicolumn{2}{|l|}{34} & 18.0 \\
\hline & 21-25 Years & \multicolumn{2}{|l|}{12} & 6.3 \\
\hline & 26-30 Years & \multicolumn{2}{|l|}{17} & 9.0 \\
\hline & $31+$ Years & \multicolumn{2}{|l|}{19} & 10.1 \\
\hline & Total & \multicolumn{2}{|l|}{189} & 100.0 \\
\hline Previous & Experience with IPE & & Frequency & Percent \\
\hline NO pres & ious experience of IPE & & 85 & 45.0 \\
\hline YES I h & ave previous experience & eaching & 82 & 43.4 \\
\hline Total & & & 167 & 88.4 \\
\hline System & & & 22 & 11.6 \\
\hline Total & & & 189 & 100.0 \\
\hline Perceive & d Skill Level Using IPE & & Frequency & Percent \\
\hline Valid & No IPE Skills & & 18 & 9.5 \\
\hline & Few IPE Skills & & 54 & 28.6 \\
\hline & Moderate Amo & E Skills & 70 & 37.0 \\
\hline & Quite a bit of I & & 21 & 11.1 \\
\hline & My skills are $p$ & in IPE & 5 & 2.6 \\
\hline & Total & & 168 & 88.9 \\
\hline Missing & System & & 21 & 11.1 \\
\hline Total & & & 189 & 100.0 \\
\hline
\end{tabular}




\begin{tabular}{llcc} 
Geographical Location of ATEP within the Institution & Frequency & Percent \\
\hline Valid & NO My ATEP is not housed in & 108 & 57.1 \\
& Allied Health & & \\
& YES My ATEP is housed in Allied & 74 & 39.2 \\
& Health & 182 & 96.3 \\
& Total & 7 & 3.7 \\
Missing & System & 189 & 100.0 \\
Total & & & \\
\hline
\end{tabular}


Table 2

One-Way ANOVA of Perceived Level of Readiness by Previous Experience with IPE

\begin{tabular}{lrrrrr}
\hline & \multicolumn{1}{c}{ SS } & df & \multicolumn{1}{c}{ MS } & F & p \\
\hline Between Groups & 40.028 & 2 & 20.014 & 19.925 & .000 \\
Within Groups & 144.639 & 144 & 1.004 & & \\
Total & 184.667 & 146 & & & \\
\hline
\end{tabular}

Note. Significance at the $\mathrm{p}<.05$ level. 
Table 3

One-Way ANOVA of Perceived Role and Responsibilities by Perceived Skill Level of IPE

\begin{tabular}{lrrrrr}
\hline & SS & \multicolumn{1}{c}{ df } & \multicolumn{1}{c}{ MS } & \multicolumn{1}{c}{ F } & p \\
\hline Between Groups & 150.114 & 4 & 37.528 & 31.633 & .000 \\
Within Groups & 183.886 & 155 & 1.186 & & \\
Total & 334.000 & 159 & & & \\
& & & & & \\
\hline
\end{tabular}

Note. Significance at the $\mathrm{p}<.05$ level. 
Table 4

One-Way ANOVA of Perceived Roles and Responsibilities by Independent Variable of Having Previous Experience Teaching with IPE

\begin{tabular}{lrrrrc} 
& \multicolumn{1}{c}{ SS } & Df & \multicolumn{1}{c}{ MS } & F & p \\
\hline Between Groups & 76.561 & 2 & 38.280 & 23.404 & .000 \\
Within Groups & 258.433 & 158 & 1.636 & & \\
Total & 334.994 & 160 & & & \\
\hline
\end{tabular}

Note. Significance at the $\mathrm{p}<.05$ level. 
Table 5

One-Way ANOVA of Skill Level of IPE on Perceived Knowledge of IPE

\begin{tabular}{lrrrrc} 
& \multicolumn{1}{c}{ SS } & df & MS & F & p \\
\hline Between Groups & 7.961 & 4 & 1.990 & 4.707 & .001 \\
Within Groups & 65.111 & 154 & .423 & & \\
Total & 73.071 & 158 & & & \\
\hline
\end{tabular}

Note. Significance at the $\mathrm{p}<.05$ level. 
Table 6

One-Way ANOVA of ATEP Location on Teamwork and Collaboration

\begin{tabular}{lrrrrr} 
& \multicolumn{1}{c}{ SS } & df & MS & F & p \\
\hline Between Groups & 2.403 & 2 & 1.202 & 3.270 & .041 \\
Within Groups & 54.761 & 149 & .368 & & \\
Total & 57.164 & 151 & & & \\
\hline
\end{tabular}

Note. Significance at the $\mathrm{p}<.05$ level. 
Table 7

One-Way ANOVA of Independent Variable of Rank or Role on Perceived Barriers

\begin{tabular}{|c|c|c|c|c|c|c|}
\hline & & $\begin{array}{l}\text { Sum of } \\
\text { Squares }\end{array}$ & $\mathrm{df}$ & $\begin{array}{l}\text { Mean } \\
\text { Square }\end{array}$ & $\mathrm{F}$ & Sig. \\
\hline \multirow[t]{4}{*}{ Lack of Leadership } & Between & 35.540 & 8 & 4.443 & 2.342 & .022 \\
\hline & Groups & & & & & \\
\hline & Within Groups & 254.208 & 134 & 1.897 & & \\
\hline & Total & 289.748 & 142 & & & \\
\hline \multirow[t]{4}{*}{ Political Tension } & Between & 37.086 & 8 & 4.636 & 2.329 & .023 \\
\hline & Groups & & & & & \\
\hline & Within Groups & 266.760 & 134 & 1.991 & & \\
\hline & Total & 303.846 & 142 & & & \\
\hline \multirow{4}{*}{$\begin{array}{l}\text { Resistance to } \\
\text { Change }\end{array}$} & Between & 30.241 & 8 & 3.780 & 2.178 & .033 \\
\hline & Groups & & & & & \\
\hline & Within Groups & 232.571 & 134 & 1.736 & & \\
\hline & Total & 262.811 & 142 & & & \\
\hline \multirow[t]{4}{*}{ Timetable } & Between & 27.116 & 8 & 3.389 & 2.239 & .028 \\
\hline & Groups & & & & & \\
\hline & Within Groups & 201.314 & 133 & 1.514 & & \\
\hline & Total & 228.430 & 141 & & & \\
\hline \multirow{4}{*}{$\begin{array}{l}\text { Lack of Time to } \\
\text { Develop New IPE } \\
\text { activities }\end{array}$} & Between & 26.774 & 8 & 3.347 & 2.301 & .024 \\
\hline & Groups & & & & & \\
\hline & Within Groups & 194.932 & 134 & 1.455 & & \\
\hline & Total & 221.706 & 142 & & & \\
\hline
\end{tabular}

Note. Significance at the $\mathrm{p}<.05$ level. 
Table 8

One-Way ANOVA of Independent Variable Years of Teaching Experience on Perceived Barriers to IPE

\begin{tabular}{|c|c|c|c|c|c|c|}
\hline & & $\mathrm{SS}$ & $\mathrm{df}$ & MS & $\mathrm{F}$ & $\mathrm{p}$ \\
\hline \multirow[t]{4}{*}{ Lack of Leadership } & Between & 25.020 & 6 & 4.170 & 2.142 & .052 \\
\hline & Groups & & & & & \\
\hline & Within Groups & 264.729 & 136 & 1.947 & & \\
\hline & Total & 289.748 & 142 & & & \\
\hline \multirow{4}{*}{$\begin{array}{l}\text { Resistance to } \\
\text { Change }\end{array}$} & Between & 22.896 & 6 & 3.816 & 2.163 & .050 \\
\hline & Groups & & & & & \\
\hline & Within Groups & 239.915 & 136 & 1.764 & & \\
\hline & Total & 262.811 & 142 & & & \\
\hline \multirow[t]{4}{*}{ Curriculum } & Between & 31.881 & 6 & 5.313 & 2.697 & .017 \\
\hline & Groups & & & & & \\
\hline & Within Groups & 266.014 & 135 & 1.970 & & \\
\hline & Total & 297.894 & 141 & & & \\
\hline \multirow[t]{4}{*}{ Class Sizes } & Between & 27.989 & 6 & 4.665 & 2.375 & .033 \\
\hline & Groups & & & & & \\
\hline & Within Groups & 267.101 & 136 & 1.964 & & \\
\hline & Total & 295.091 & 142 & & & \\
\hline \multirow{4}{*}{$\begin{array}{l}\text { Lack of Time w/ } \\
\text { existing IPE } \\
\text { activities }\end{array}$} & Between & 26.017 & 6 & 4.336 & 2.468 & .027 \\
\hline & Groups & & & & & \\
\hline & Within Groups & 237.166 & 135 & 1.757 & & \\
\hline & Total & 263.183 & 141 & & & \\
\hline
\end{tabular}

Note. Significance at the $\mathrm{p}<.05$ level. 
Table 9

One-Way ANOVA of Independent Variable ATEP Location on Perceived Barriers

\begin{tabular}{lrrrrr}
\hline & SS & df & MS & F & p \\
\hline Between Groups & 88.560 & 2 & 44.280 & 15.747 & .000 \\
Within Groups & 382.433 & 136 & 2.812 & & \\
Total & 470.993 & 138 & & & \\
\hline \multicolumn{6}{c}{} \\
\hline Statistic & & & & & \\
\hline Welch & 13.534 & df1 & df2 & p \\
\hline
\end{tabular}


Table 10

One-Way ANOVA of Previous Experience with Teaching IPE on Perceived Barriers

\begin{tabular}{llrrrrc}
\hline & & \multicolumn{1}{c}{ SS } & df & \multicolumn{1}{c}{ MS } & \multicolumn{1}{c}{ F } & p \\
\hline Lack Knowledge & Between Groups & 27.666 & 1 & 27.666 & 18.669 & .000 \\
& Within Groups & 204.506 & 138 & 1.482 & & \\
& Total & 232.171 & 139 & & & \\
\hline Lack of Time to & Between Groups & 11.076 & 1 & 11.076 & 7.327 & .008 \\
Develop New IPE & Within Groups & 210.130 & 139 & 1.512 & & \\
activities & Total & 221.206 & 140 & & & \\
\hline
\end{tabular}


Table 11

One-Way ANOVA of the Independent Variable of Perceived Skill Level Using IPE on Perceived Barriers

\begin{tabular}{llrrrrc}
\hline & & \multicolumn{1}{c}{ SS } & \multicolumn{1}{c}{ df } & MS & F & p \\
\hline Lack of Knowledge & Between Groups & 39.879 & 4 & 9.970 & 7.074 & .000 \\
& Within Groups & 193.086 & 137 & 1.409 & & \\
& Total & 232.965 & 141 & & & \\
\hline
\end{tabular}




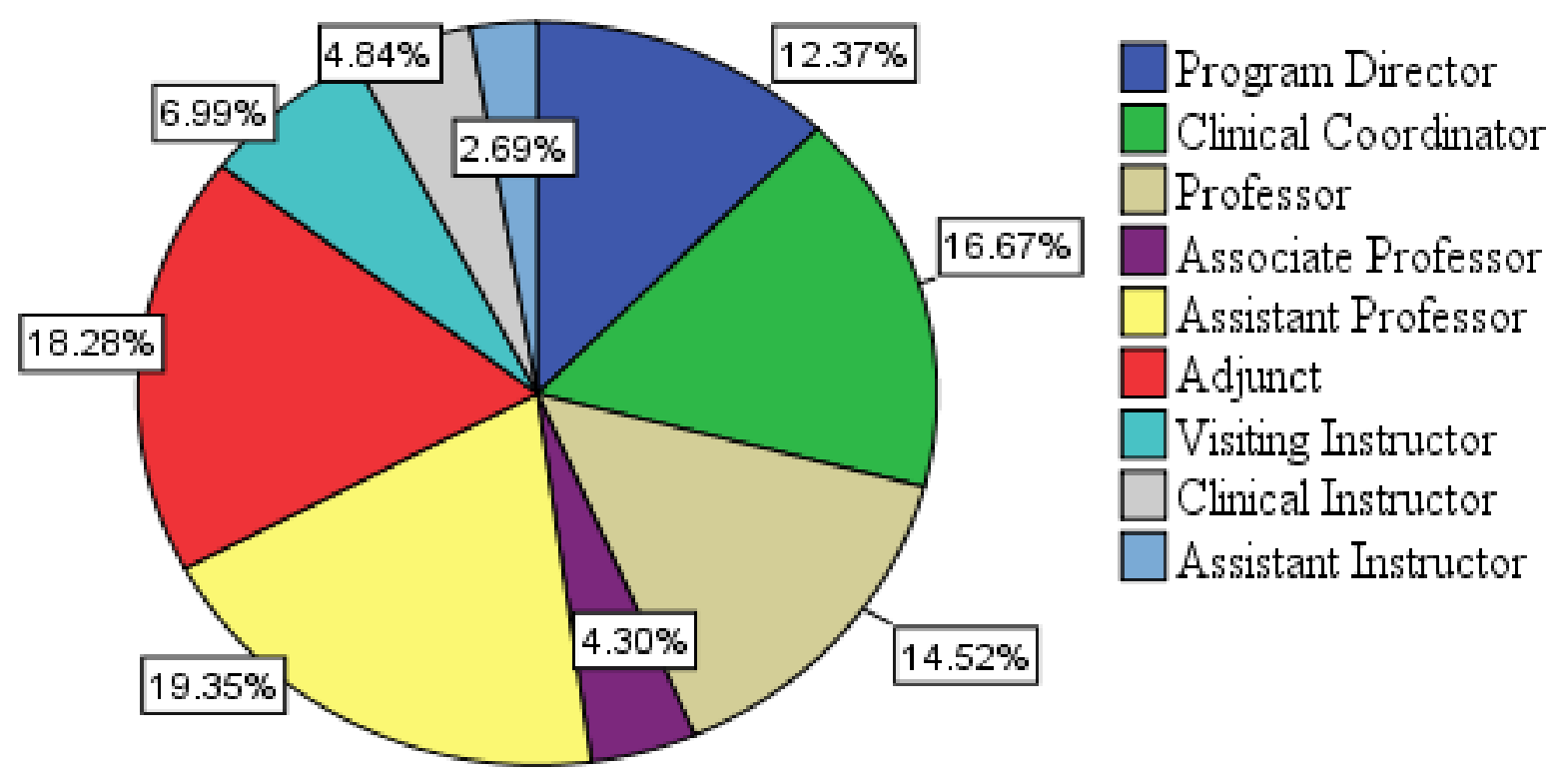

Figure 1. Demographics of Faculty Rank or Role. 

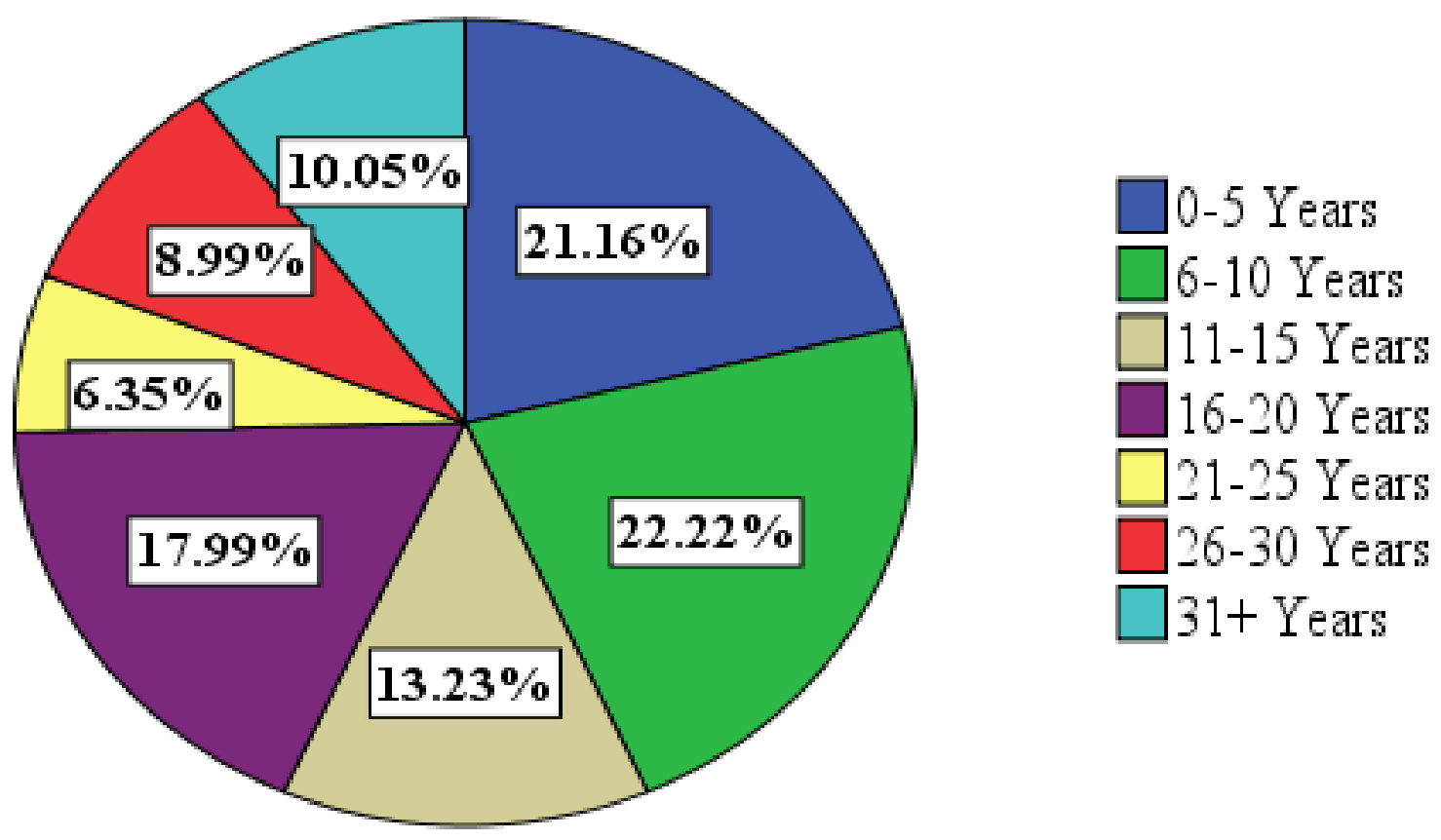

Figure 2. Demographics for Years of Teaching Experience. 


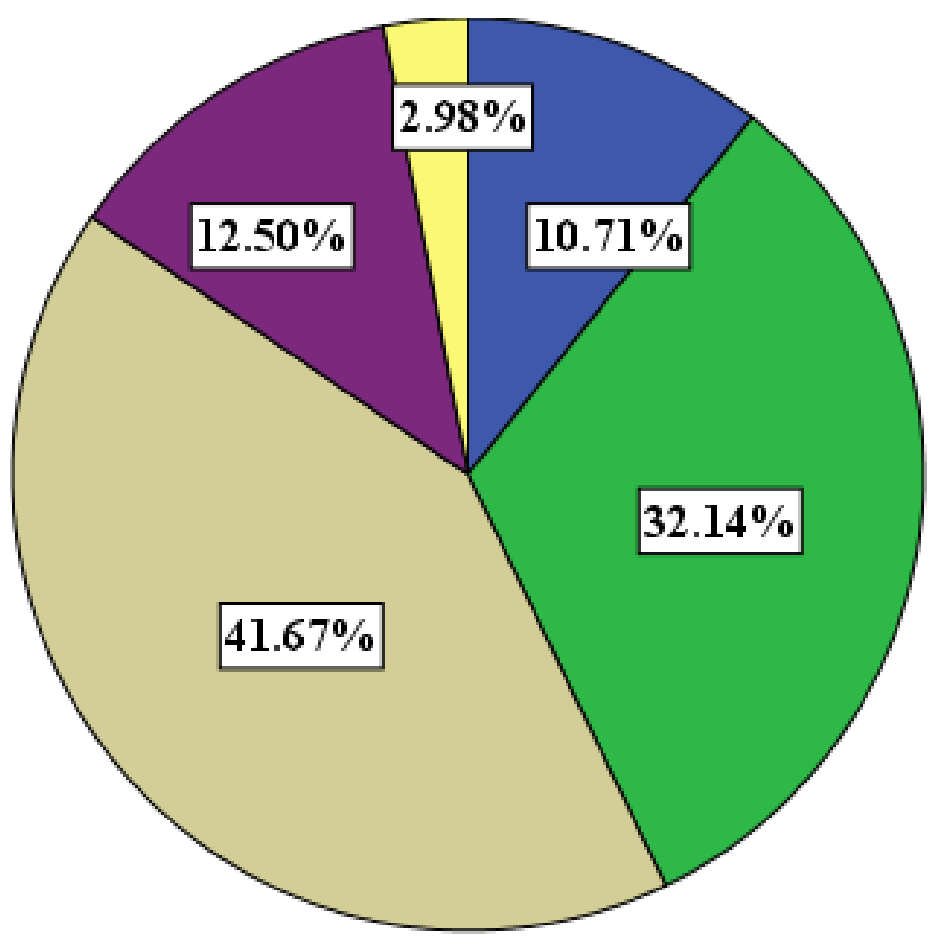

$\square$ No IPE Skills

$\square$ Few IPE Skills Moderate

$\square$ Amount of IPE Skills

Quite a bit of IPE Skills

$\square^{\text {My skills are }}$ proficient in IPE

Figure 3. Perceived Skill Level Using IPE Demographics 


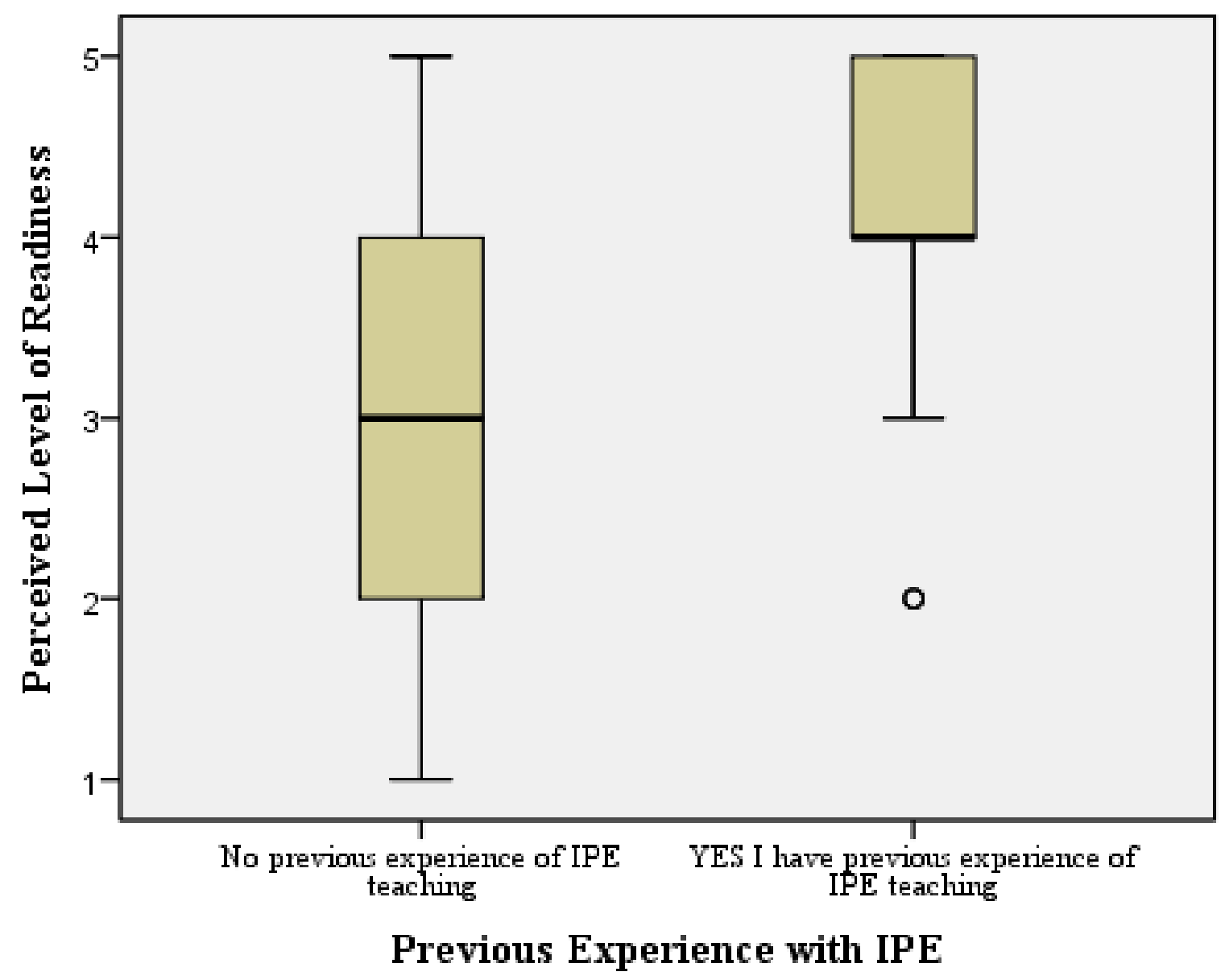

Figure 4. Independent Variable of Perceived Level of Readiness based on the Dependent Variable of Previous Experience with Teaching IPE. 


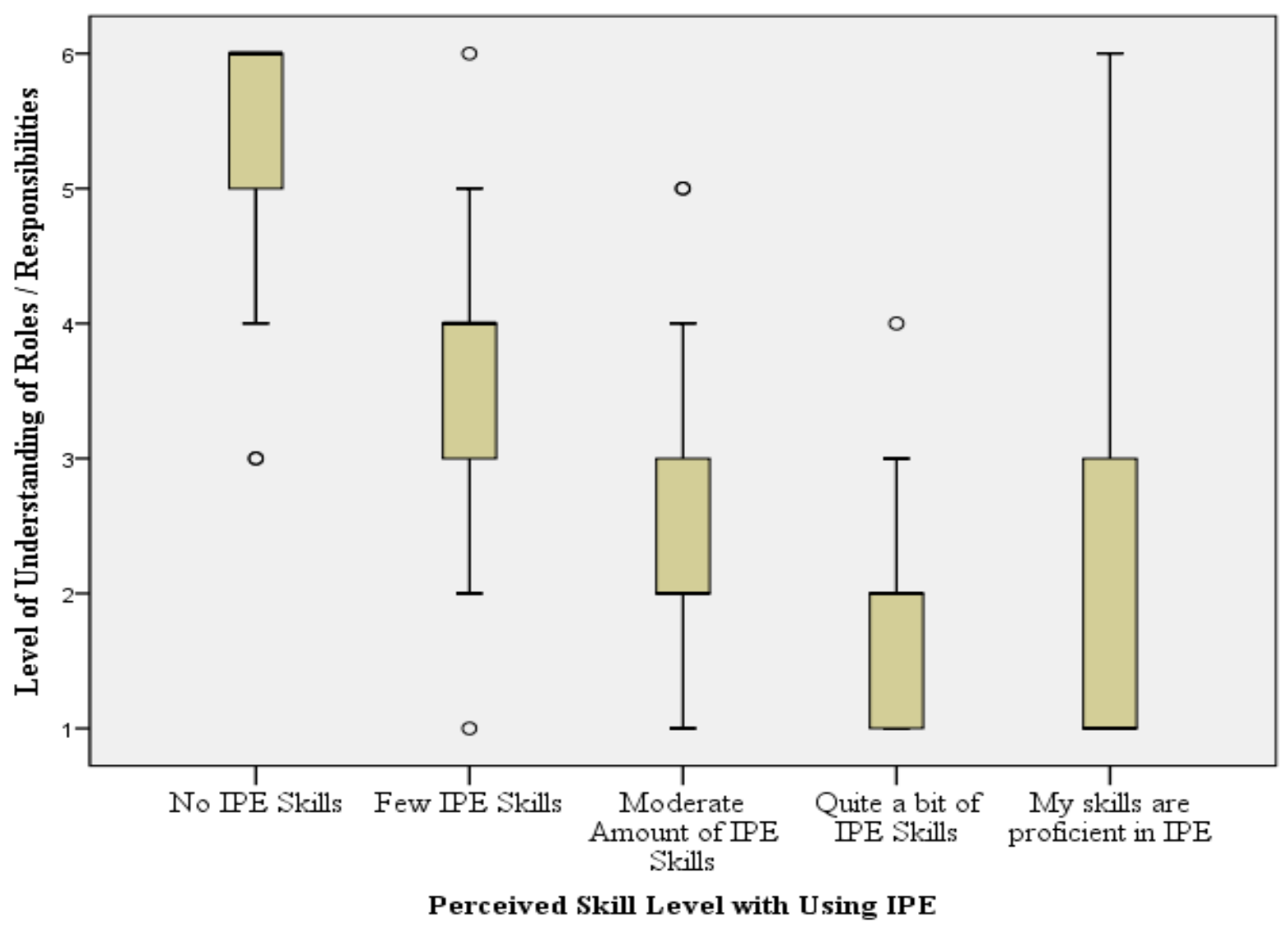

Figure 5. Faculty perceived levels of uncertainty regarding roles and responsibilities for interprofessional learning dependent on perceived skill level with using IPE. 


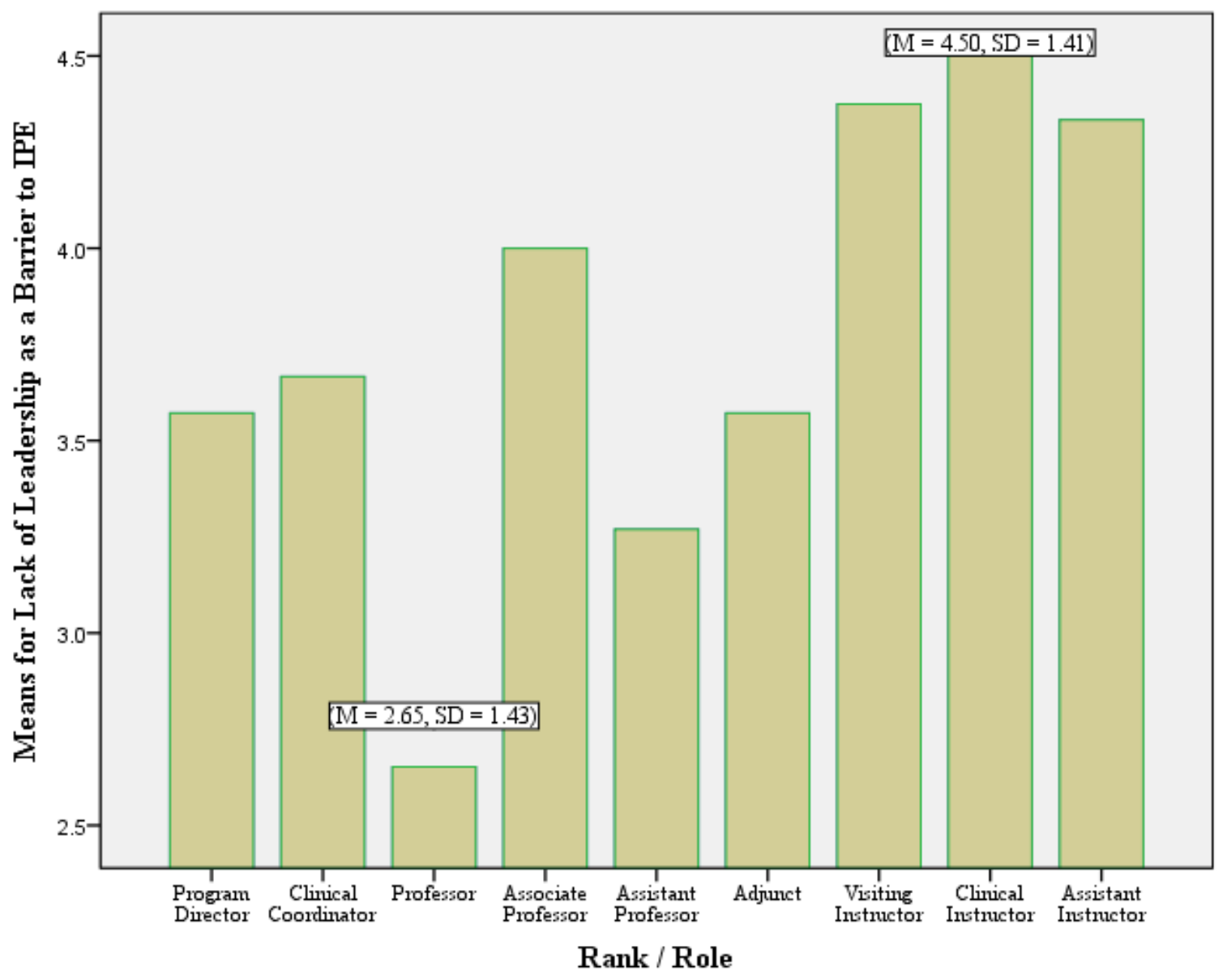

Figure 6. Means for lack of leadership as a perceived barrier based on faculty rank or role. 


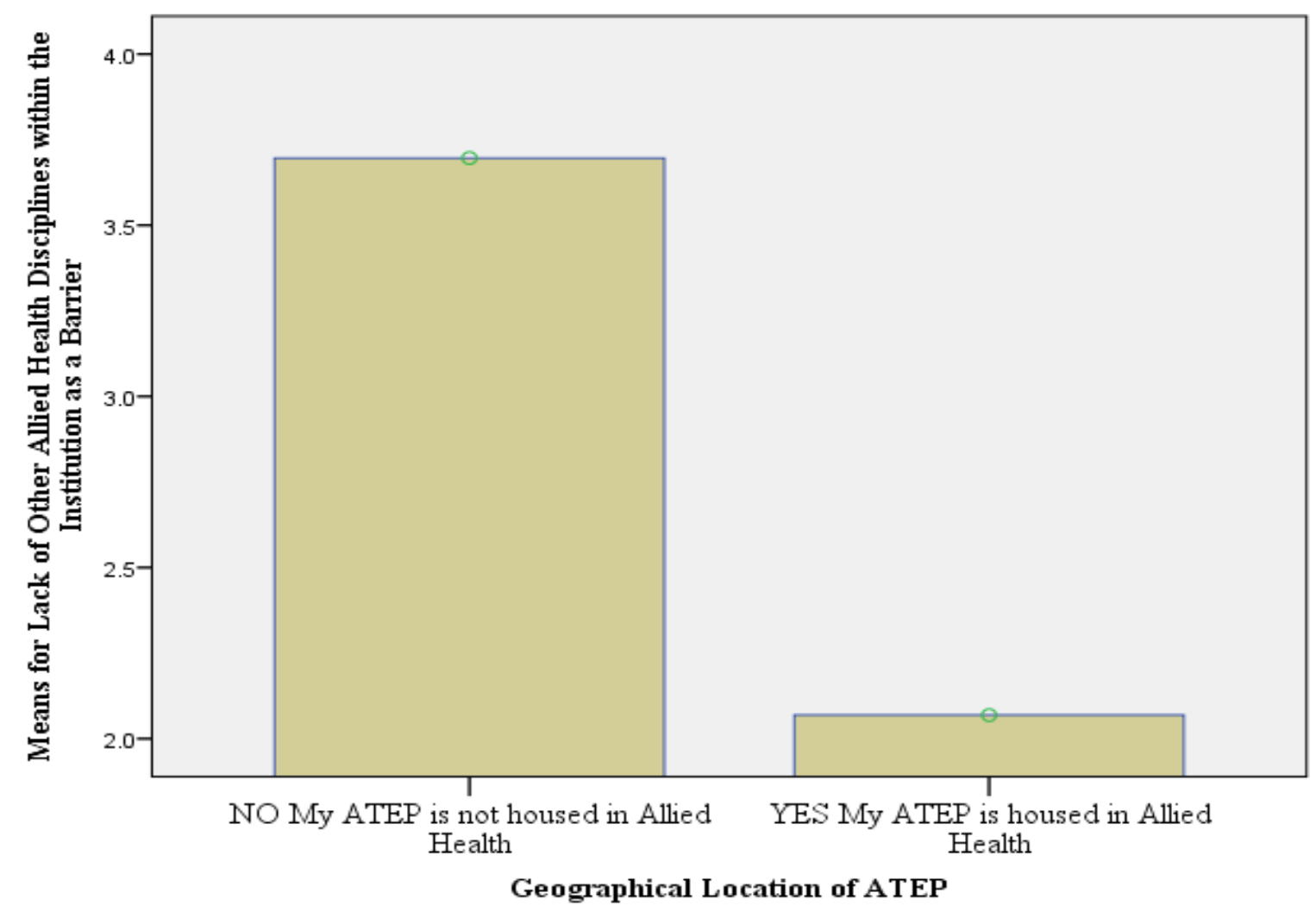

Figure 7: Means for Lack of Other Allied Health Disciplines at the Institution based on Geographical Location of ATEP within the Institution. 
Appendix A

\section{Demographics}

1. Age: $\square 21-30 \quad \square$ 31-40 $\square$ 41-50 $\square$ 51-60 $\square$ 61-70

2. Faculty Rank/Role: Program Director / Clinical Coordinator / Professor/ Associate Professor / Assistant Professor / Adjunct / Visiting Instructor / Clinical Instructor / Assistant Instructor

3. Years of Experience Teaching:

4. Years of Clinical Practice:

$$
\text { 0-5yrs/ 6-10yrs /11-15yrs /16-20yrs /21-25yrs/26-30yrs } / 31+\text { years }
$$

0-5yrs/ 6-10yrs /11-15yrs /16-20yrs /21-25yrs/26-30yrs $/ 31+$ years

5. Education Route to Certification: Internship to certification / Undergraduate / Graduate

6. Have you had previous experience of interprofessional teaching? $\square$ Yes $\square$ No If you answered yes to the previous question, please give a very brief statement of what this IPE teaching was.

7. Please rate your frequency in using IPE strategies within your teaching. $(1=$ never, $2=$ once per academic year, $3=$ once per semester, $4=$ once a month, $5=$ once a week; 6 = everyday)

8. How would you rate your skill level in integrating IPE into your teaching? ( $1=$ not proficient; $6=$ extremely proficient)

\section{Perceptions of IPE}

Please indicate your level of agreement with the following statements by using the 5-point rating scale provided. ( $1=$ strongly disagree; $2=$ disagree; $3=$ neutral; $4=$ agree; $5=$ strongly agree $)$.

1. Individuals in my profession are well-trained

2. Individuals in my profession are able to work closely with individuals in other professions

3. Individuals in my profession demonstrate a great deal of autonomy

4. Individuals in other professions respect the work done by my profession

5. Individuals in my profession are very positive about their goals and objectives

6. Individuals in my profession need to cooperate with other professions

7. Individuals in my profession are very positive about their contributions and accomplishments

8. Individuals in my profession must depend upon the work of people in other professions

9. Individuals in other professions think highly of my profession

10. Individuals in my profession trust each other's professional judgment

11. Individuals in my profession have a higher status than individuals in other professions

12. Individuals in my profession make every effort to understand the capabilities and contributions of other professions

13. Individuals in my profession are extremely competent

14. Individuals in my profession are willing to share information and resources with other professionals

15. Individuals in my profession have good relations with people in other professions

16. Individuals in my profession think highly of other related professions

17. Individuals in my profession work well with each other 
18. Individuals in other professions often seek the advice of people in my profession

19. I would welcome the opportunity to work on curriculums with faculty from other colleges

20. I must acquire more knowledge of IPE than faculty from other colleges

21. Individuals in my college need to cooperate with other colleges

22. I believe IPE has positive outcomes for practice

23. I believe that IPE will promote health outcomes among patients

24. I am unsure of my role in IPE

25 . Individuals in my college need to cooperate with other colleges

26. Communication skills should be taught with faculty from other colleges

27. Students will ultimately benefit if faculty from different colleges teach collaboratively

28. To teach IPE effectively, team-working skills are essential for all health care faculty

29. On a scale of 1-6, please rate your level of readiness to implement IPE in your teaching? ( $1=$ not ready; $6=$ proficient $)$

30. Where do you currently obtain your knowledge on IPE strategies?

\section{Barriers to IPE}

31. Lack of Leadership

32. Political tension

33. Resistance to change

34. Timetable

35. Class sizes

36. Curriculum

37. Accreditation

38. Workload

39. Lack of knowledge

40. Lack of time with existing IPE activities

41. Lack of time to develop new IPE activities

42. Lack of interest

43. Lack of pedagogical support

44. Lack of technological support

45. Consuming logistics to coordinate

46. Please provide suggestions/needs for overcoming the perceived barriers your selected. 


\section{Appendix B}

Dear Fellow Certified Athletic Trainer,

I am a doctoral candidate for the University of St. Augustine for Health Sciences, requesting your help to complete part of my degree requirements. Please follow the link at the end of this letter to complete an online survey titled: Readiness to Implement Interprofessional Education in Athletic Training: Faculty Perceptions.

This survey is not approved or endorsed by the NATA. It is being sent to you because NATA's commitment to athletic training education and research.

One thousand randomly selected certified NATA members with a listed email address are being asked to submit this questionnaire, but you have the right to choose not to participate. The University of St. Augustine's Institutional Review Board has approved this study for the Protection of Human Subjects.

This is a completely anonymous questionnaire and upon submission, neither your name nor email address will be attached to your answers. Your information will be kept strictly confidential. By submitting a completed survey you are hereby providing your informed consent for utilization of your responses.

As a fellow certified athletic trainer, your knowledge and opinions regarding this topic makes your input invaluable. The questionnaire should only take about 10-15 minutes to complete. Please follow the link below to complete the questionnaire and submit your responses.

\section{https://www.surveymonkey.com/r/ReadinessToImplementIPEinAT}

If you have any questions/comments/ or concerns regarding your participation in this study please direct them to the principal investigator: Meredith Parry, MS, LAT, ATC by phone: (305) 613-3534 or via email: m.parry@ usa.edu. If you continue to have concerns you may contact the Dissertation Committee Chair: Dr. Jordan Utley, PhD, LAT, ATC by phone: (214) 250-0349 or via email: Jutley@usa.edu.

If these resources are not able to address your concerns, you may contact the University Chair of the IRB for the University of St. Augustine, Florida campus: Dr. Lisa Chase, or Dr. Jeffrey Rot, Co-Chairs, University of St. Augustine for Health Sciences Institutional Review Board, 904-8260084 x1234, 1chase@usa.edu or jrot@usa.edu.

Thank you for your time and consideration.

Sincerely, Meredith Parry 